\title{
MUÑOCES, MARCILLAS Y OTRAS FAMILIAS DOMINANTES EN LA CIUDAD DE TERUEL \\ $(1435-1500)^{1}$
}

\author{
GERMÁN NAVARRO ESPINACH ${ }^{2}$
}

Fecha de recepción: mayo 2002

Fecha de aceptación y versión final: julio 2002

Resumen: El objeto de este artículo es realizar un estudio de las élites urbanas de Teruel en el siglo XV, a base de muchas fuentes complementarias procedentes de los archivos históricos de la ciudad. El concepto de burguesía se pone de manifiesto mejor que otras posibilidades de análisis. En el trabajo se explica la prosopografía de dieciseis familias, después de haber identificado alrededor de doscientas personas que participaron en el gobierno municipal de Teruel durante muchos años, en ese período cronológico.

Palabras clave: Burguesía, Concejo, Prosopografía, Siglo XV, Aragón, Teruel, Ciudades.

Abstract: The present article tries to stablish a study of the 15th century urban élites of Teruel with a lot of complementary records from the historical archives of the city. Concept of bourgeoisie is remarked as better than other possibilities of analysis. Prosopography of sixteen families are considered, after we have identified near two hundred people who had participated in the goverment of the town council during many years in that period.

Key-words: Bourgeoisie, Town council, Prosopography, 15th century, Aragon, Teruel, Cities.

${ }^{1}$ El presente estudio se integra en el proyecto de investigación Prosopografia de las sociedades urbanas en Aragón, siglos XIV-XV. Estrategias sociales y comportamientos individuales en los grupos dirigentes urbanos, financiado por la Dirección General de Ciencia y Tecnología del Gobierno Español para el período 2001-2003 (referencia BHA2000-1342) y del que forman parte José Ángel Sesma Muñoz (investigador principal), Juan J.F. Utrilla Utrilla, Carlos Laliena Corbera y Germán Navarro Espinach.

${ }^{2}$ Departamento de Historia Medieval, Ciencias y Técnicas Historiográficas, y Estudios Árabes e Islámicos, Facultad de Filosofía y Letras, Universidad de Zaragoza.

«Anuario de Estudios Medievales», 32/1 (2002), pp. 723-775 .- ISSN 0066-5061. 


\section{SUMARIO}

1. Debate conceptual.- 2. Bibliografía y fuentes para el estudio prosopográfíco-3. Los Sánchez Muñoz.- 4. Los Marcilla.- 5. Otras familias dominantes.- 5.1. Abad.- 5.2. Besanta.- 5.3. Camañas.- 5.4. Campos.- 5.5. Jarque.- 5.6. Mata.- 5.7. Moros.- 5.8. Navarro.- 5.9. Pérez Arnal.- 5.10. Puigmitjà.- 5.11. Ram.- 5.12. Ruiz.- 5.13. Sánchez Gamir.- 5.14. Santángel.- 6. Resultados generales.- Apéndice $n^{\circ}$ 1: Genealogía de los Sánchez Muñoz.- Apéndice $n^{\circ}$ 2: Listado de personas que ocuparon los cargos más importantes del concejo de Teruel durante 1444-1500.

\section{DEBATE CONCEPTUAL}

Son variados los términos con que se alude a los grupos dirigentes urbanos en la Edad Media. La mayoría de historiadores ha preferido las expresiones oligarquía y elites urbanas. Con el concepto oligarquía se referiría mejor y con un carácter más universal a la clase dominante de las ciudades bajomedievales, que asimismo viene siendo definida como patriciado urbano por la integración de grupos sociales distintos, coincidentes en una acción de intereses y de gobierno. Mientras tanto, la fórmula elites urbanas pretende expresar la discontinuidad del tejido social de las ciudades, y a la vez también la totalidad del cuerpo social, pues haría referencia a un entramado de solidaridades complejas en el que se identifica una minoría en posición de superioridad social, económica, política o cultural. Incluso, el término elite introduciría un reconocimiento de identidad colectiva en el grupo que organiza una sociedad de no iguales. En suma, oligarquía y elites urbanas intentan sustituir conscientemente a otros conceptos historiográficos como el de burguesía o nobleza urbana con menor número de adeptos ${ }^{3}$.

Sin embargo, aunque no haya tenido tanto éxito, no creo que el concepto burguesía sea más tosco ni más limitado historiográficamente en

\footnotetext{
${ }^{3}$ Véase la introducción de Rafael Narbona (coordinador) al dossier Oligarquías políticas y élites económicas en las ciudades bajomedievales (siglos XIV-XVI), en "Revista de Historia Medieval", 9 (1998), pp. 12-13. Por añadidura, puede consultarse el nuevo dossier Ciudades y élites urbanas en el Mediterráneo medieval, coordinado por Paulino Iradiel y Rafael Narbona, publicado en "Revista d'Història Medieval", 11 (2000).

«Anuario de Estudios Medievales», 32/1 (2002), pp. 723-775 .- ISSN 0066-5061.
} 
su definición social que oligarquía o elites urbanas, ajenos ambos, por otra parte, al léxico medieval. En contraste, el término burgueses sí que aparece en la documentación europea de la época, tal y como sucede en el reino de Aragón a finales del siglo XI. En efecto, el fuero de Jaca de 1077 ya clasificaba a los pobladores francos de dicha ciudad entre caballeros, burgueses y rústicos ${ }^{4}$. Desde entonces, el burgués quedó definido sobre todo por su libertad dentro del mundo feudal, con las franquicias específicas que conllevaba en el ámbito urbano, a la vez que por la naturaleza peculiar de su actividad económica, centrada en la industria, el comercio o el ejercicio de una profesión liberal. Así lo entendía en el siglo XIII el obispo Vidal de Canellas, quien definió a los burgueses como aquellos que vivían en ciudades y cuyo medio de vida consistía en la explotación de una industria con operarios, en el comercio al por mayor, en el ejercicio bancario (cambistas), o en alguna actividad profesional (juristas, notarios, médicos, etc.). En la Baja Edad Media, esta burguesía no dejó de desarrollarse en Aragón conquistando nuevas libertades que se reflejaron en las correspondientes ordenanzas municipales, mientras se constituía en la capa superior de la sociedad que habitaba en las ciudades gracias a su riqueza patrimonial y al control de los gobiernos locales ${ }^{6}$.

Además, algunos autores como García de Cortázar e Iradiel, entre otros, se han pronunciado a favor de recuperar el uso del concepto burgue-

${ }^{4} \mathrm{La}$ expresión en latín es vel miles vel burgensis aut rusticus, véase M.L. LEDESMA RUBIO, Cartas de población del Reino de Aragón en los siglos medievales, Zaragoza, Institución Fernando el Católico, 1991, doc. 2, p. 27.

${ }^{5}$ M.D. CABANES; A. BlasCo; P. PuEYo, Vidal Mayor. Edición, introducción y notas al manuscrito, Zaragoza, Libros Certeza, 1997. La cita textual en la p. 247 dice así: Cipdadanos son todos aqueillos qui moran en las cipdades o en las villas que son como cipdades, de los quoales logares aqueillos son ditos burgeses los quoales, maguer ayan cabdaleros et servientes por los quoales trayen los sus officios, empero no usan eillos por sus manos aqueillos officios, empero son unos officios que maguer por sus manos usen, no son itados de la orden de los burgeses, assí como son aqueillos qui venden los paynnos de precio et camiadores et sobre todo esto vozería o fisica o çirurgía et otras cosas igoales déstas ho mayores.

${ }^{6} \mathrm{C}$. LALIENA Corbera; M.T. Iranzo MuNíio, Poder, honor y linaje en las estrategias de la nobleza urbana aragonesa (siglos XIV-XV) en "Revista d'Història Medieval", 9 (1998), pp. 41-80.

«Anuario de Estudios Medievales», 32/1 (2002), pp. 723-775 .- ISSN 0066-5061. 
sía en las investigaciones actuales ${ }^{7}$. En mi opinión, parece la fórmula historiográfica más coherente para interpretar el fenómeno de las elites urbanas y no cabe duda que, tras un período de descalificación, lleno de implicaciones ideológicas, el término burguesía comienza a ser afortunadamente normalizado, aunque sea bajo el manto de oligarquías mercantiles o de la mano de los modernistas ${ }^{8}$. También es cierto que raramente se concreta cuáles eran las familias que la formaban, cuáles eran sus bases de poder y cómo habían llegado a ocupar una posición dominante en el mundo urbano. En definitiva, ¿de qué manera habría que delimitar ese perfil social en las ciudades bajomedievales?

No creo que deba hacerse evaluando simplemente sus aptitudes o roles desde una perspectiva sociológica funcionalista, donde resulta muy difícil explicar la reproducción social del grupo. Tampoco es útil plantearlo mediante cierto marxismo vulgar obsesionado exclusivamente en desentrañar la estructura de clases sólo a través de quién detenta o no la propiedad de los medios de producción en la sociedad, algo necesario para el análisis pero insuficiente en última instancia. Pienso que, más bien, deviene fundamental adoptar un concepto dinámico de evolución social en línea con un materialismo histórico más prudente e integrador, en cuyo observatorio subyazcan claves explicativas como la familia, el sistema educativo, el mercado laboral y de capitales, o la organización política (el Estado), mecanismo principal éste último de la reproducción del sistema. ¿Cuáles fue-

${ }^{7}$ J.A. GARCÍA DE CORTÁZAR, El fortalecimiento de la burguesía como grupo social dirigente en la sociedad vascongada a lo largo de los siglos XIV y XV en "La sociedad vasca rural y urbana en el marco de la crisis de los siglos XIV y XV", Bilbao, 1973, pp. 283-313; P. IRADIEL MURUGARREN, Ciudades, comercio y economia artesana en "La historia medieval en España. Un balance historiográfico (1968-1998)", XXV Semana de Estudios Medievales de Estella (14-18 julio 1998), Pamplona, 1999, pp. 603-658, especialmente p. 614, nota 31. Véase también C. BATLLE, Las familias de la alta burguesía en el municipio de Barcelona (siglo XIII) en "Anuario de Estudios Medievales", 16 (1986), pp. 81-92; M.R GARCíA ARANCON, Burguesía y realeza en Navarra a mediados del siglo XIII en "Anuario de Estudios Medievales”, 18 (1988), pp. 139-146; A. RUCQUOI, Las oligarquias urbanas y las primeras burguesías en Castilla en "El tratado de Tordesillas y su época". Madrid, 1995, pp. 345-369; y J.J. BUSQUETA I RIU, Burgesia i mentalitat feudal a la Lleida del segle XIV en "Homenatge a mossén Jesús Tarragona", Ajuntament de Lleida, 1996, pp. 189-218.

${ }^{8}$ La burguesía española en la Edad Moderna, 2 vols., Universidad de Valladolid, 1996 (actas de un congreso internacional celebrado en la Universidad Complutense de Madrid en 1991).

«Anuario de Estudios Medievales», 32/1 (2002), pp. 723-775 .- ISSN 0066-5061. 
ron, por tanto, las estrategias que puso en juego la burguesía para perpetuarse en su hegemonía social dentro de las ciudades bajomedievales??

El método prosopográfico es una de las fórmulas de investigación más fructíferas para poder responder a esa pregunta. La experiencia llevada a cabo por el equipo de medievalistas dirigido por Paulino Iradiel en la Universidad de Valencia supone un referente importante al respecto ${ }^{10}$. La prosopografía ha sido el primado metodológico que ha dado mayor coherencia si cabe al esfuerzo colectivo realizado, al permitir cruzar las bases de datos elaboradas individualmente por todos los componentes del equipo. De hecho, cada vez más claramente, un número creciente de estudios biográficos ha demostrado la posibilidad de reconstruir la vida y la singularidad de los hombres y mujeres del pasado, para poder comprender las características de grupos sociales complejos. Pequeñas y grandes historias individuales a través de las cuales se pretende abordar todo el entramado de específicas interferencias entre sociedad local, vida política y acción económica. Hay que tipificar comportamientos en sincronía y diacronía mediante fuentes archivísticas heterogéneas. Tras ello, se trata de organizar la información obtenida en listados prosopográficos que permitan elaborar genealogías, destinadas a reconstruir trayectorias familiares de clase y redes clientelares en sentido político, esto es, que sirvan para ejercer el poder en la ciudad.

\section{BIBLIOGRAFÍA Y FUENTES PARA EL ESTUDIO PROSOPOGRÁFICO}

La documentación que conserva la ciudad de Teruel en la Edad Media ofrece enormes posibilidades de contrastación de datos para elaborar prosopografías y descubrir las estrategias familiares y las vías de acceso al

${ }^{9} \mathrm{G}$. NAVARRo EsPINACH, Los negocios de la burguesía en la industria precapitalista valenciana de los siglos XIV-XVI en "Revista d'Història Medieval", 11 (2000), pp. 67-104.

${ }^{10} \mathrm{P}$. IRADIEL; G. NAVARRO; D. IGUAL, Ricerche valenzane per la storia del mondo urbano nell'Europa mediterranea (secoli XIV-XVI) en "Medioevo. Saggi e rassegne", 25 (2002), en prensa (monográfico sobre la historiografía actual en la Corona de Aragón).

«Anuario de Estudios Medievales», 32/1 (2002), pp. 723-775 .- ISSN 0066-5061. 
poder de las elites urbanas ${ }^{11}$. Para empezar, la tesis doctoral de Antonio Gargallo ya estudió la fundación y articulación política del concejo en los siglos XII-XIV a partir de numerosos pergaminos municipales y otros fondos archivísticos $^{12}$. Incluso, en un artículo específico posterior abordó la implantación de los jurados en el concejo a partir de 1208. Esos oficiales representaban los primeros atisbos de la conformación de un poder municipal que, junto al juez, los alcaldes, el almutazaf y otros cargos, extraídos anualmente voluntate et arbitrio concilii entre los propietarios de caballos que integraban la comunidad, asumían el peso de la gestión cotidiana del gobierno urbano turolense ${ }^{13}$. Responsables máximos de la seguridad de la villa y de la supervivencia misma de la comunidad, los caballeros se irían perfilando desde muy temprano como los más cualificados para la dirección de la vida urbana y la defensa y organización de los intereses comunitarios. Ello significaba, sin duda, el encumbramiento político y social de una reducida minoría desde el siglo XIII. Paralelamente, sólo desde el último tercio de esta centuria pudo darse por finalizado el proceso de elaboración del fuero de Teruel ${ }^{14}$.

Con todo, una disposición de Jaime I, fechada en 1262, ponía de manifiesto que muchos caballeros, una vez habían accedido al cargo correspondiente, se desprendían de sus caballos, estableciendo el rey que quien hiciese tal cosa tendría un plazo perentorio de 30 días para adquirir otro.

${ }^{11} \mathrm{G}$. NAVARRO EsPINACH, Teruel en la Edad Media. Balance y perspectivas de investigación en "Aragón en la Edad Media", XIV-XV (1999), Homenaje a la profesora Carmen Orcástegui Gros, vol. II, pp. 1199-1225.

${ }^{12} \mathrm{~A}$. Gargallo Moya, El Concejo de Teruel en la Edad Media, 1177-1327, 3 vols., Teruel, Instituto de Estudios Turolenses, 1996. Véase también del mismo autor, Teruel en la Edad Media: de la frontera a la crisis (1171-1348) en "Teruel mudéjar. Patrimonio de la Humanidad", Zaragoza, Ibercaja, 1991, pp. 9-105. Téngase en cuenta que la tesis doctoral de Gargallo fue publicada en su texto original completo (a falta de un cuarto volumen de documentos), tras su fallecimiento en 1996, aunque dicho texto se defendió el 28 de septiembre de 1990. Mientras tanto, la síntesis para el volumen de Teruel mudéjar es el único resumen de dicha tesis que llegó a publicar el autor al año siguiente de haberla defendido. En consecuencia, la obra editada en 1996 es más antigua que la síntesis de 1991.

${ }^{13} \mathrm{~A}$. Gargallo Moya, Conflicto social y reforma municipal. La implantación de los jurados en el concejo de Teruel (1208) en "Aragón en la Edad Media", IX (1991), pp. 7-24.

${ }^{14}$ Véase asimismo J. CASTAÑÉ LlinÁs, El Fuero de Teruel, edición crítica con introducción y traducción, Zaragoza, 1989. Las versiones del fuero de Teruel que se conocen hoy en día fueron redactadas entre 1260 y 1265 , no son el texto original de 1177.

«Anuario de Estudios Medievales», 32/1 (2002), pp. 723-775 .- ISSN 0066-5061. 
De igual manera, las cortes de Zaragoza de 1350 se quejaban abiertamente de que los carniceros, peleteros, herreros y, en general, los artesanos aspiraban fácilmente a gobernar la villa comprando un caballo, por lo que Pedro IV estableció que además cesaran en sus oficios un año antes de desempeñar cualquier cargo concejil ${ }^{15}$. Ciertamente, el desarrollo económico de Teruel era manifiesto desde años atrás, cuando en 1294 comenzó a celebrarse la feria local de ganado durante dos semanas desde el 24 de agosto, siendo ampliada otra semana más en $1383^{16}$. Recuérdese asimismo que, en el último tercio del siglo XIII, el señor de la villa o persona que la tuviese en nombre del rey desapareció por completo, siendo sustituido por una nueva autoridad, el justicia, designado también por el monarca solamente para determinadas actuaciones o períodos. Lo encontramos por vez primera en 1261-1262. A partir de entonces, el cargo popular de juez o presidente del concejo se fue consolidando como la máxima autoridad efectiva de Teruel, electo anualmente de entre las personas que tuvieran caballo y además casa puesta en la villa. Desde luego, las prosopografías de señores y justicias de Teruel demuestran que éstos fueron miembros de la nobleza ajenos por completo a la estructura social de la villa ${ }^{17}$.

La evolución política local avanzaba hacia una consolidación evidente. A la altura de 1277, las aldeas de Teruel habían instituido su comunidad frente al señorío de la villa y, setenta años después, en 1347, Pedro IV le concedía a ésta el título de ciudad. Por esas fechas, la población fiscal de Teruel sumaba un total de 1.525 contribuyentes según el monedaje de 1342-1343, de los cuales 103 quedaron dispensados del pago por su condición de caballeros. En el monedaje de 1384-1387, el número total de contribuyentes había descendido un tercio tras la Peste Negra de 1348 (930 personas), siendo únicamente 66 los exentos de pago en calidad de caballe-

${ }^{15}$ J. CARUANA Gómez DE BARREDA, Caballeros y caballos en el Medievo turolense en "Teruel", 15-16 (1956), pp. 241-247. 134.

${ }^{16}$ J. Caruana Gómez de Barreda, La Feria de Teruel en "Teruel”, 37 (1967), pp. 129-

${ }^{17} \mathrm{~J}$. CARUANA GómeZ DE BARREDA, Los señores de Teruel en los siglos XII y XIII en “Teruel”, 17-18 (1957), pp. 43-125. Véase también del mismo autor, El poder real y su intervención en las luchas fratricidas de Teruel hasta el año 1500, así como su continuación en $E l$ poder real y su intervención en las luchas fratricidas de Teruel hasta el año 1600, ambos en "Teruel", 45-46 (1971) y 48 (1972), pp. 241-308 y 5-59 respectivamente.

«Anuario de Estudios Medievales», 32/1 (2002), pp. 723-775 .- ISSN 0066-5061. 
ros. Por contra, los datos disponibles para el siglo XV ilustran una clara tendencia demográfica a la baja en Teruel. Varios cuadernos de contribución vecinal de los años 1420 a 1431, conocidos como compartimientos, permiten establecer una población en torno a los 800 fuegos, mientras que los hogares asignados en las contribuciones del reino en 1489-1491 o 1495 se sitúan en 500 o 400 unidades fiscales respectivamente ${ }^{18}$. Como ha podido observarse, desde el siglo XIV los caballeros representaban tan sólo un 7 por ciento de la población oficial de la ciudad. En efecto, los resortes de la jurisdicción concejil habían sido acaparados por una minoría de rentistas que se perpetuó en el poder, generación tras generación, dándose el caso, incluso, de haber más cargos disponibles que candidatos hábiles para ocuparlos: el juez, cuatro alcaldes, el escribano o padrón, el almutazaf o mayordomo, dos procuradores, ocho o siete jurados (según el número de parroquias), los cinco regidores o inspectores económicos, y además un nutrido grupo de empleados subalternos que desempeñaban las tareas más diversas.

Con esas circunstancias, para poder elaborar un estudio prosopográfico profundo de las elites urbanas en Teruel, el siglo XV constituye el período más documentado desde fuentes diversas. A grandes rasgos, la secuencia cronológica de estudio iría desde el monedaje de 1384-1387 hasta el fogaje de 1495 , sumando un centenar y medio de pergaminos del concejo, la serie continua de manuales de actos desde 1398, los compartimientos de 1429-1431, diversos protocolos notariales que abarcan todo el siglo (incluidos los tres puntualmente conservados en Zaragoza), la documentación del hospital de Santa María y San Juan y, por supuesto, el guión oficial de los acontecimientos que recogen las crónicas de los jueces de Teruel, los procesos de la Inquisición contra judaizantes o la documentación eclesiástica estudiada por César Tomás, Alberto López Polo y Vidal Muñoz ${ }^{19}$. Entre

\footnotetext{
${ }^{18}$ Gargallo, Teruel en la Edad Media, cit., p. 63. Véase también L. Orera ORERA; G. REDONDO VEINTEMILLAS, Fuentes para la historia demográfica y social de Teruel: compartimientos de 1420 a 1431 en "Estado actual de los estudios sobre Aragón", Actas de las Primeras Jornadas celebradas en Teruel, 18-20 diciembre 1978, vol. I, pp. 273-276.

${ }^{19}$ F.J. Aguirre Gonzalvez y otros, Catálogo de los Archivos Municipales Turolenses (IV), Teruel, 1985, pp. 185-252 (Archivo Municipal de Teruel); F. LóPEZ RAJADEL, Crónicas de los Jueces de Teruel (1176-1532), Teruel, 1994; C. TOMÁs LAGUíA, Catálogo de los pergaminos y documentos insertos en ellos, existentes en el Archivo de la S. I. Catedral de Te-

«Anuario de Estudios Medievales», 32/1 (2002), pp. 723-775 .- ISSN 0066-5061.
} 
todas esas fuentes, nuestro proyecto de investigación junto a Sesma, Utrilla y Laliena, citado en la nota inicial del presente artículo, quiso abordar la amplísima documentación todavía inédita, haciéndolo desde una perspectiva prosopográfica. En ese sentido, el listado por orden cronológico de los materiales que centraron la atención de dicho proyecto es el siguiente, con alusión específica en su caso a las cajas y documentos del Archivo Municipal de Teruel donde se localizan:

1384-1387 Morabedí de Teruel y sus aldeas (publicado por Ledes$\mathrm{ma})^{20}$

1398-1399 Manual de Concejo (caja 7, doc. 21)

1411-1412 Manual de Concejo (caja 8, doc. 22)

1412-1413 Manual de Concejo (caja 8, doc. 23)

1414-1415 Manual de Concejo (caja 8, doc. 24)

1415 Protocolo notarial de Sancho Boyl (caja 34, doc. 1)

1417-1418 Manual de Concejo (caja 8, doc. 25)

1419 Protocolo notarial de Juan Sánchez de Santa María (caja 12, doc. 1)

1420 Protocolo notarial de Juan Sánchez de Santa María (caja 12, doc. 2)

1420 Compartimiento de la pecha de la ciudad de Teruel (caja 17, doc. 1)

1421 Compartimiento de la pecha de la ciudad de Teruel (caja 17, doc. 1)

1422 Compartimiento de la pecha de la ciudad de Teruel (caja 17, doc. 1)

1422 Protocolo notarial de Juan Sánchez de Santa María (caja 13, doc. 3)

1422-1423 Manual de Concejo (caja 6, doc. 19)

1423 Compartimiento de la pecha de la ciudad de Teruel (caja 17, doc. 1)

1423 Protocolo notarial de Sancho Boyl (caja 13, doc. 4)

ruel, Teruel, 1953; A. LÓPEZ Polo, Catálogo del Archivo del Capítulo General Eclesiástico, Teruel, 1965; C. TOMÁs LAGuía, Indice de los documentos en papel del Archivo de la Catedral de Teruel, correspondientes a los siglos XII, XIII, XIV y XV en "Teruel", 48 (1972); y V. MuÑOZ GARRIDO, La ciudad de Teruel de 1347 a 1597. Cómo éramos los turolenses en la Epoca Medieval, 2 vols., Teruel, 2000. $13-42$.

${ }^{20}$ M.L. LedESMA RuBIO, Morabedi de Teruel y sus aldeas, Zaragoza, Anubar, 1982, pp.

«Anuario de Estudios Medievales», 32/1 (2002), pp. 723-775 .- ISSN 0066-5061. 
1424 Compartimiento de la pecha de la ciudad de Teruel (caja 17, doc. 1)

1425 Compartimiento de la pecha de la ciudad de Teruel (caja 17, doc. 1)

1426 Compartimiento de la pecha de la ciudad de Teruel (caja 17, doc. 1)

1427 Compartimiento de la pecha de la ciudad de Teruel (caja 17, doc. 1)

1427 Protocolo notarial de Juan Sánchez de Santa María (caja 14, doc. 5)

1427-1428 Protocolo notarial de Sancho Boyl (caja 14, doc. 6)

1428 Manual de Concejo (caja 6, doc. 20)

1429 Compartimiento de la pecha de la ciudad de Teruel (caja 17, doc. 1)

1430 Protocolo notarial de Juan Sánchez de Santa María (caja 14, doc. 7)

1431 Compartimiento de la pecha de la ciudad de Teruel (caja 17, doc. 1)

1435-1436 Protocolo notarial de Sancho Boyl (caja 14, doc. 8)

1440 Protocolo notarial de Juan Sánchez de Santa María (caja 34, doc. 2)

1442 Protocolo notarial de Juan Sánchez de Santa María (caja 14, doc. 9)

1444 Protocolo notarial de Juan Sánchez de Santa María (caja 15, doc. 10)

1445-1446 Manual de Concejo (caja 5, doc. 16)

1445-1447 Protocolo notarial de Juan Sánchez de Santa María (caja 15, doc. 11)

1450-1451 Manual de Concejo (caja 5, doc. 17)

1453-1454 Manual de Concejo (caja 1, doc. 1)

1454-1455 Manual de Concejo (caja 34, doc. 3)

1455-1456 Manual de Concejo (caja 1, doc. 2)

1456-1457 Manual de Concejo (caja 15, doc. 12; caja 34, doc. 4)

1460 Manual de Concejo (caja 2, doc. 3)

1461-1462 Manual de Concejo (caja 2, doc. 4)

1462 Manual de Concejo (caja 34, doc. 5)

1462-1464 Manual de Concejo (caja 27, doc. 72)

1465-1466 Manual de Concejo (caja 2, doc. 5)

1466-1467 Manual de Concejo (caja 34, doc. 6)

1467-1468 Manual de Concejo (caja 2, doc. 6)

1468-1469 Manual de Concejo (caja 3, doc. 7)

1469-1470 Manual de Concejo (caja 3, doc. 8)

1470-1471 Manual de Concejo (caja 3, doc. 9) 
1471-1472 Manual de Concejo (caja 3, doc. 10)

1473 Protocolo notarial de Antonio de Liria (Archivo Histórico de Protocolos de Zaragoza)

1473-1474 Manual de Concejo (caja 3, doc. 11)

1474-1475 Manual de Concejo (caja 4, doc. 12)

1479-1480 Manual de Concejo (caja 4, doc. 13)

1481-1482 Manual de Concejo (caja 4, doc. 14)

1481-1518 Libro padrón del hospital de San Juan y Santa María de Teruel (publicado por Navarro) ${ }^{21}$

1483-1484 Manual de Concejo (caja 4, doc. 15)

1484-1487 Documentos de la Inquisición (publicados por Sánchez Moya, Monasterio y Ferrer $)^{22}$

1489 Protocolo notarial de Francisco Muñoz (Archivo Histórico de Protocolos de Zaragoza)

1491 Protocolo notarial de Alfonso Jiménez (Archivo Histórico de Protocolos de Zaragoza)

1495 Fogaje del reino de Aragón (publicado por Serrano) ${ }^{23}$

1499-1500 Manual de Concejo (caja 6, doc. 18)

A la hora de poder ofrecer un avance de los resultados disponibles en este número monográfico del Anuario de Estudios Medievales dedicado a las elites urbanas, precisamente, la temática de nuestro proyecto de investigación en curso, se ha preferido concretar una cronología de estudio más pequeña, a partir de 1435 , primera fecha posterior a la serie de compartimientos de los años 1420-1431. Sobre todo, los datos prosopográficos que ofrezco a continuación derivan del análisis exhaustivo de protocolos

${ }^{21}$ G. NAVARRo ESPINACH, El hospital de Santa María de Villaespesa y de San Juan Bautista en la ciudad de Teruel a través de los actos notariales de Alfonso Jiménez (1481-1518) en "Aragón en la Edad Media", XVI (2000), Homenaje al profesor emérito Ángel San Vicente Pino, pp. 565-590.

${ }^{22}$ M. SÁNCHEZ MOYA, La Inquisición de Teruel y sus judaizantes en el siglo XV. Proceso integro contra Brianda de Santángel y otras doncellas turolenses en "Teruel", 20 (1958), pp. 145-200; Los Marcilla iempachadores de la Inquisición turolense?. Proceso del Santo Oficio de la Inquisición en Teruel contra García Garcés de Marcilla en "Teruel", 27 (1962), pp. 107-129; Los Marcilla y la Inquisición turolense en "Teruel", 33 (1965), pp. 181-199; M. SÁNCHEZ MOYA; J. MONASTERIO ASPIRI, Los judaizantes turolenses en el siglo XV en "Sefarad" XXXII (1972), pp. 105-140 y 307-340, y XXXIII (1973), pp. 111-143 y 325-356; y R. FERRER NAVARRO, Aspectos económicos de la Inquisición turolense a fines del siglo XV en "Ligarzas", 7 (1975), pp. 275-302.

${ }^{23}$ A. Serrano Montalvo, La población de Aragón según el fogaje de 1495, 2 vols., Zaragoza, 1997, tomo I, pp. 257-261.

«Anuario de Estudios Medievales», 32/1 (2002), pp. 723-775 .- ISSN 0066-5061. 
notariales (1435-1436, 1440, 1442, 1444, 1445-1447, 1473, 1489 y 1491) y manuales de actos del concejo (1445-1500), en contraste con la documentación de finales del siglo XV ya editada (fogaje, inquisición y hospital), y con otras informaciones heterogéneas que derivan de la bibliografía existente. En ese sentido, trataremos para comenzar los dos grandes linajes de las elites urbanas turolenses (Muñoces y Marcillas) y luego abordaremos por orden alfabético de sus apellidos otras familias destacadas en el ámbito local, e incluso reseñaremos algunos individuos importantes que intervienen en el gobierno concejil pero que no parecen participar de una estrategia familiar colectiva, al no constar parientes suyos en el reparto de cargos políticos. Se trata de adelantar un estado de la cuestión que pueda completarse más adelante con el montante total de documentación anterior a 1435 , dominada, sin duda alguna, por las ricas informaciones patrimoniales de los compartimientos.

\section{LOS SÁNCHEZ MUÑOZ}

Sin lugar a dudas, éste fue el linaje más poderoso de Teruel desde su fundación en el siglo XII hasta la primera mitad del siglo XVI y más allá, con el desarrollo de hasta nueve generaciones distintas en el conjunto de su trayectoria familiar, tal y como puede observarse en el árbol genealógico que se reproduce en el Apéndice $n^{o} 1$, en el cual consta la línea primogénita heredera del título de la baronía de Escriche. Dicho linaje cuenta además con un fondo archivístico propio que he estudiado detenidamente y que se conserva en el Archivo Histórico Provincial de Teruel, con materiales pertenecientes al período 1346-1879 (una caja con 102 documentos) ${ }^{24}$. El antepasado más remoto que se ha documentado es Sancho Sánchez Muñoz, quien tomó parte activa en la propia toma de Teruel, recibiendo del rey parte de las tierras conquistadas junto a otros caballeros. Se sabe que estuvo casado con Marquesa, de cuyo matrimonio nacieron dos hijos, Pas-

\footnotetext{
${ }^{24}$ R. SERrANo GonZÁlez, Archivo Histórico Provincial de Teruel, Zaragoza, Gobierno de Aragón, 1995, pp. 101-102. Una parte del archivo familiar de los Sánchez Muñoz se encuentra en el Archivo de la Corona de Aragón dentro de la Sección Diversos Varia en el fondo de Babra, y otra se conserva en la Biblioteca de Cataluña.

«Anuario de Estudios Medievales», 32/1 (2002), pp. 723-775 .- ISSN 0066-5061.
} 
cual y Martín Muñoz, los cuales participaron juntos en la batalla de las Navas de Tolosa en 1212 al servicio del rey Pedro II de Aragón ${ }^{25}$. Precisamente, fue Pascual Muñoz quien se convirtió en el primer barón y señor de la villa de Escriche, por concesión del rey Alfonso II en reconocimiento a los méritos contraídos por su padre en la conquista y fundación de Teruel, a las que asistió él mismo siendo todavía muy joven ${ }^{26}$. Lo cierto es que durante 1205-1206 ocupó el cargo de juez del concejo y, tiempo después, la crónica de Jaime I elogiaba al tal Pascual Muñoz por la ayuda prestada al rey para la conquista del reino de Valencia: E don Pasqual Monyós, qui era molt privat de nostre pare, era dels mellors hòmens de vila que nós haguéssem en nostra terra en aquell temps; e dix-nos que ens prestaria molt volenters e de grat tot quant ell pogués, de si e de sos amics. E presta'ns per tres setmanes tot ço que haviem mester... ${ }^{27}$. Estuvo casado, al parecer, con Marquesa Gálvez y de este matrimonio nacieron cinco hijos (Gil, Sancho, Juan Gil, Francisco y Antonio).

Gil Sánchez Muñoz y Gálvez fue el primogénito del citado Pascual, a quien sucedió en la baronía y señorío de Escriche, asistiendo como capitán a la conquista de Valencia, y al cual aludía también la crónica de Jaime I cuando pidió el monarca ayuda a los prohombres del concejo de Teruel: E, quan hagren estat una poca hora tornaren a nós, e respòs Gil Sanxes Munyoz per tots aquells de la vila, e dix:-Senyor, ben sabedes vos que unca en lo que vos demandastes nin rogastes non trobastes de no en nos, ni lo fisiestes ni lo faredes agora: decimos vos que vos enprestaremos tres milia cargas de pan, mil de trigo, e dos milia d'ordio, veinte milia carne-

\footnotetext{
${ }^{25}$ Para la reconstrucción genealógica de este linaje véase BARÓN DE LA LINDE, Noticia histórico-genealógica de los Sánchez Muñoz de Teruel, señores de Finojosa, Barones de la villa y castillo de Escriche y de la Linde. Ordenada por su primogénito actual el Barón de la Linde, Valencia, 1911; y G. GARCÍA CIPRÉS, Los Sánchez-Muñoz de Teruel en "Linajes de Aragón”, tomo III (1912), pp. 81-87, 97-103, 117-122, 137-141 y 157-161. Consúltense asimismo C.J. WITTLIN, Noticias del archivo medieval de la familia Sánchez Muñoz, de Teruel en "Teruel”, 44 (1970), pp. 5-26; y V. MuÑoz GARRIDO, El linaje de los Sánchez Muñoz en Teruel (1170-1500) en "Aragón en la Edad Media”, XVII (2001), en prensa.

${ }^{26}$ Escriche es un lugar a $17 \mathrm{~km}$ de Teruel, situado en el barranco del mismo nombre y en donde se conserva abandonado el viejo palacio de la baronía.

${ }^{27}$ LóPeZ RAJAdel, Crónicas de los jueces, cit., p. 80; y JAUME I, Crònica o Llibre dels Feits, edición de Ferran SoldEvilA, Barcelona, Edicions 62 i La Caixa, 1982, cap. 25, p. 62.

«Anuario de Estudios Medievales», 32/1 (2002), pp. 723-775 .- ISSN 0066-5061.
} 
ros, et tres milia vacas: e si queredes más prendet de nós ${ }^{28}$. Desde luego, consta que ocupó el cargo de juez al menos en 1260-12619. Estuvo casado con Catalina Martínez de Marcilla y tuvieron seis hijos (Pedro, Sancho, Juan Gil, Sendina, Francisco y Antonio). Y en esos años en que el rey Jaime I conquistaba Murcia (1265-1266), se recoge la primera referencia histórica a que ...levantaronse los menudos contra los mayores en la villa de Teruel, castigolos el rey ${ }^{30}$.

Pedro Sánchez Muñoz y Martínez de Marcilla (1250-1316), primogénito de Gil, sucedió a éste en el título de la baronía y señorío de Escriche, además de poseer el señorío de Torralba por su matrimonio con Galaciana de Liñán, perteneciente a una familia noble de Calatayud. Del matrimonio nacieron cuatro hijos (Pedro, Gil, Ramón y Juan). En su testamento mandó que fuese enterrado en la iglesia de Santa María de Teruel. También ocupó como su padre y su abuelo el cargo de juez, concretamente durante $1286-1287^{31}$.

Pedro Sánchez Muñoz y Liñán, a pesar de ser el primogénito de la quinta generación del linaje no disfrutó de la baronía de Escriche, la cual había pasado a García Rodrigo de Urrea y posteriormente a Lope de Concud $^{32}$. Por otra parte, Pedro estuvo casado con Catalina Sánchez de Carbón, de cuyo matrimonio nacieron cinco hijos: Gil, Pedro, Alonso, Catalina y Francisca. En 1324, cuenta la crónica del juez que ...pelearon los Marziellas et Munyozes en Teruel el Jueves Santo ${ }^{33}$. Es la primera vez que se documenta el enfrentamiento entre este linaje y el de sus rivales los Marcilla, teniendo por causa quizá la posesión de la citada baronía de Escriche, como se reconocerá más tarde en el siglo XVI. Y todavía en 1343 graves sucesos acontecieron en la familia a causa de la lucha de bandos,

\footnotetext{
${ }^{28}$ Crònica o Llibre dels Feits, cit., cap. 407, pp. 337-338.

${ }^{29}$ López RAJADEL, Crónicas de los jueces, cit., p. 102.

${ }^{30}$ Ibídem, p. 104.

${ }^{31}$ Ibídem, p. 112.

${ }^{32}$ Lope de Concud, según el estudio genealógico del Barón de la Linde, debió ser hijo de Juan Sánchez Muñoz y Liñán, y de Elvira López de Concud, que tomaría el apellido de su madre, como era costumbre repetidas veces en aquella época.

${ }^{33}$ López RAJADEL, Crónicas de los jueces, cit., p. 132. 
hasta el punto de apresar al juez y a los alcaldes de Teruel por no hacer justicia: ...porque fue muerto el fi de Gil Sanchez Munoz en los bandos el dia de San Juan e no quisieron prender al matador ${ }^{34}$. Al respecto, un documento de 1355, conservado en el Archivo Histórico de Protocolos de Zaragoza, contiene una relación interesante de los desmanes cometidos en Teruel a causa del enfrentamiento entre estos dos linajes ${ }^{35}$.

El fondo de los Sánchez Muñoz en el Archivo Histórico Provincial de Teruel conserva el testamento inédito del hijo primogénito del tal Lope de Concud, que le sucedió en la baronía de Escriche. Su nombre era Juan Sánchez Muñoz y realizó su última voluntad el 8 de diciembre de 1346 junto a su esposa Elvira López, figurando ambos como señores de Escriche y vecinos de la villa de Teruel. Este Juan alude a su padre en cierto párrafo de su testamento diciendo: Dios perdone al honrado Lope de Concut padre nuestro qui fue aqui. Además, los cónyuges establecieron que deseaban ser enterrados en el convento de San Francisco de Teruel, en la capilla o lugar del claustro do jaçe soterrado el honrado et savio Sancho Sanchez Munyoz qui fue mandado por el edifficar o obrar a la puerta de la yglesia et al portal de la sagristanya. No podemos afirmar si ese Sancho era aquel caballero que fue hermano de Pedro, tercer barón y señor de Torralba. Otros datos de interés que proporciona este testamento son los nombres de sus siete hijos: Gil (primogénito y heredero de la baronía), Juan (segundón que heredará las rentas de la escribanía de la corte de Morella concedida por el rey a Lope de Concud), Luis, Pedro, Francisca, Sendina y Elvira ${ }^{36}$. Por añadidura, un dato complementario sobre el destino que tuvo la baronía de Escriche tras el testamento en cuestión proviene de los años 1368-1369, cuando conste como juez de Teruel un tal Juan Sánchez Muñoz, ostentando el

\footnotetext{
${ }^{34}$ Ibidem, p. 143.

${ }^{35} \mathrm{~A}$. JAVIERRE MUR, Los bandos de los Marcillas y los Muñoces en Teruel en el siglo XIV en "Revista de Archivos, Bibliotecas y Museos", tercera época, XXI/XXXVI, enero-junio 1917 (1918), pp. 369-377.

${ }^{36}$ Archivo Histórico Provincial de Teruel (=AHPT), Fondo de la Familia Sánchez-Muñoz, doc. 1. El testamento fue elaborado por Adán Pérez de Viana, notario de Teruel, y consta una copia posterior del notario Jordán Benedito a instancia de un tal Francisco Sánchez Muñoz, escudero de Teruel, con fecha 12 de febrero de 1375. Dicho fondo conserva cuarenta documentos inéditos fechados entre 1346 y 1551 que he consultado para profundizar más en la historia de esta familia, al margen de las series archivísticas ya enumeradas.
} 
título de senyor de la villa d'Escriche y el calificativo de mayor de dias, aunque al año siguiente actuará contra él el propio rey deponiéndolo de su cargo $^{37}$. Y tampoco en los años finales del siglo XIV se libró Teruel de los enfrentamientos entre las dos familias rivales de la ciudad, puesto que en 1382 Vino el infant don Johan a Teruel et puso paz et tregua entre Marziellas et Munyozes y todavía en 1397 Bolvieronse los bandos en Terue ${ }^{38}$.

Apartada pues la rama principal del linaje de ostentar la baronía (hasta que pudo recuperarla en el siglo XVI), el primogénito de su sexta generación, Gil Sánchez Muñoz y Carbón (1370-1447), acabaría convirtiéndose en el antipapa Clemente VIII (1424-1429) y, posteriormente, tras su abdicación, en obispo de Mallorca hasta su muerte. Respecto a su persona, el Archivo Municipal de Teruel posee bastantes documentos, algunos de los cuales, centrados en el tema de su renuncia a la herencia de la familia, han sido ya dados a conocer ${ }^{39}$. Con todo, la mejor biografía existente hasta ahora corresponde a un artículo antiguo de Manuel García Miralles ${ }^{40}$, en el que manifestaba el problema de identificación de este personaje, debido a que fueron coetáneos cuatro miembros de esta familia con el mismo nombre (Gil), eclesiásticos todos y disfrutando casi de las mismas prebendas. Los cargos desempeñados por nuestro Gil, bachiller y doctor en decretos, una vez ordenado sacerdote y con anterioridad al papado, fueron el de chantre de Gerona, cura párroco de Cullera y de Sueca, rector de Onteniente, canónigo y vicario general de la diócesis de Valencia, arcipreste de Santa María de Teruel y beneficiado patrimonial en la iglesia turolense de San Martín. Se le conocía con el sobrenombre de "Doncel", por no haber sido armado caballero aunque pertenecía a un viejo linaje de juristas, clérigos y cortesanos. Según García Miralles, la documentación conservada sobre los motivos de su elección alude a que era una persona poderosa y rica, que con sus veinte o treinta mil florines de rentas podía vivir holgadamen-

\footnotetext{
${ }^{37}$ LÓPEZ RAJADEL, Crónicas de los jueces, cit., pp. 188 y 190.

${ }^{38}$ Ibidem, pp. 210 y 220.

${ }^{39}$ C.L. DE LA VeGa y LuQue, Tres documentos inéditos sobre Gil Sánchez Muñoz en "Teruel”, 55-56 (1976), pp. 51-57.

${ }^{40} \mathrm{M}$. GarCía Miralles, La personalidad de Gil Sánchez Muñoz y la solución del Cisma de Occidente en "Teruel", 12 (1954), pp. 63-122.

«Anuario de Estudios Medievales», 32/1 (2002), pp. 723-775 .- ISSN 0066-5061.
} 
te. Como es lógico por ser obispo de esa diócesis tras la renuncia, su sepulcro se conserva en la antesala capitular de la Catedral de Palma de Mallorca.

Pedro Sánchez Muñoz y Carbón (fallecido entre 1430 y 1431), hijo segundón de Pedro y hermano de Clemente VIII, se casó en primeras nupcias con su prima segunda Violante Sánchez Muñoz y Muñoz, llamada la "Muñoceta", hija única del barón de Ayodar, Abdón Sánchez Muñoz y Martínez de Ladrón, uniéndose con dicho matrimonio las dos ramas de Muñoces de Aragón y Valencia ${ }^{41}$. Pero Violante murió joven y sin sucesión, dejando heredero de todos sus bienes y de cuantos derechos pudieran corresponderles a su esposo, quien contrajo después segundas nupcias con María Marín de Urríes, noble dama aragonesa, celebrándose la boda en Zaragoza. De este enlace nacieron cinco hijos (Pedro, Fadrique, Gil, Aldonza y Dionisio). Con todo, en el año 1427 la guerra de bandos seguía vigente: En este anyo fizo fer el rey pazes a Marçiellas et Munyozes de Teruel por cient et hun anyo ${ }^{42}$. Poco tiempo después, hacia 1430-1431 se hacía constar que ... murio de landre Pero Sanchez Munioz en San Francisco de Teruel, este fue aguelo de Gaspar Sanchez Munioz de Teruel y padre de mosen Pero Sanchez Munioz ${ }^{43}$.

En esas circunstancias, llegados ya los años centrales del siglo XV, nos encontramos con la trayectoria de Pedro Sánchez Muñoz y Urríes (1430-1483), el primogénito de Pedro y por tanto sobrino de Clemente VIII, que casaría muy tardíamente, un año antes de su muerte, con Catalina Sánchez Gamir, hija del mercader Miguel Sánchez Gamir. Sin embargo, a pesar de la escasa duración del matrimonio pudo dejar un único descendiente del linaje en la persona de su hijo Gaspar Juan. A lo largo de su vi$\mathrm{da}$, Pedro, honorable caballero, fue lugarteniente del procurador real y autor de unas Letras de batalla que mantuvo en correspondencia con Huguet de Pachs, comendador militar de Menorca, reuniendo más de cien libros en

\footnotetext{
${ }^{41}$ Abdón era hijo de Francisco Sánchez Muñoz y Gálvez, y de Juana Martínez Ladrón. Este Francisco casó en segundas nupcias con Elisa Ruiz de Urríes y tuvo larga descendencia, siendo su hijo Luis el origen de la rama valenciana de los Sánchez Muñoz.

${ }^{42}$ López RAJADEL, Crónicas de los jueces, cit., p. 236.

${ }^{43}$ Ibidem, p. 239.
}

«Anuario de Estudios Medievales», 32/1 (2002), pp. 723-775 .- ISSN 0066-5061. 
su biblioteca entre voluminosas crónicas y traducciones catalanas de clásicos y seudoclásicos ${ }^{44}$. De hecho, se conoce el inventario de los bienes que albergaba su lujoso palacio turolense del siglo XV, solar y hogar de la vieja e ilustre familia, estancia por estancia: la entrada, el palacio grande, el corral, el palacio donde dormían los mozos, la bodegueta, la habitación de un esclavo, los graneros, la cocina y su repostico, la recocina, la cámara donde dormía el propio mosén Pedro, la habitación de las mozas, la sala mayor y su capilla, la cámara mayor de dicha sala y otros espacios, además de diversas piezas de plata, oro y joyas, o el cofre de la señora viuda. Incluso el notario describió los bienes raíces de los Sánchez Muñoz en Teruel, indicando su situación exacta, las rentas anuales y cuándo y a quiénes se debían pagar: siete casas con sus corrales, huertos y bodegas (una casa con horno), el molino llamado del "Cubo", varios huertos, múltiples piezas de tierra y eras, con un total de 300 sueldos censales anuales pagaderos sobre todo a Santa María, al prior del clero de Teruel y a San Andrés ${ }^{45}$.

En vida de Pedro (la séptima generación de los Sánchez Muñoz en Teruel), los altercados con los Marcilla tampoco dejaron de producirse. Así en 1444 se dice que fue comovido el pueblo et los de una parte tenian su voluntad, otros no. Et vinieron a lançar piedras en la plaça mayor los unos contra los otros. Catorce años más tarde, en 1458, nuevamente ...los vandos de Marzillas et Muniozes se bolvieron et fizieron pelea en la plaça asaz fuerte et nafraronse unos a otros en plena visita de la infanta y su hijo. Pero todavía este enfrentamiento secular entre las dos familias no se había terminado, puesto que aún en 1525 se explicaban claramente los motivos de tan gran disputa: En esti año por muerte de mosen Garcia Martinez de Marzilla, canonigo de Santa Maria de Teruel, fueron grandes diferencias entre Marzillas y Muñozes y ampramiento de jente de la una parte y de la otra y por el visorrey de Aragon mosen Juan de Lanuça fue encomendada la Varonia de Escriche, sobre la qual era la quistion, a los jurados de Cor-

\footnotetext{
${ }^{44}$ Entre ellos aparecen dos obras de Boccaccio, el Corbaccio y la Lettera consolatoria a messer Pino de' Rossi, tal y como puso de manifiesto D. ROMANO, Manuscrito boccacciano del siglo XV en la Corona de Aragón en "Filología Moderna", XV/55 (junio 1975), pp. 491497.

${ }^{45}$ C.J. WitTlin, Un inventario turolense de 1484: los Sánchez Muñoz, herederos de Clemente VIII en "Teruel", 51 (1974), pp. 59-82.

«Anuario de Estudios Medievales», 32/1 (2002), pp. 723-775 .- ISSN 0066-5061.
} 
valan hasta que dicha causa fuese declarada por justicia. Finalmente, en 1531, la baronía objeto de disputa fue dada en sentencia de la Audiencia Real a Gaspar Juan Sánchez Muñoz y desde entonces quedó para siempre en manos de esta familia, tras haber estado durante todo el siglo XV, como veremos más adelante, en poder de sus enemigos los Marcilla ${ }^{46}$. Por añadidura, en el fondo familiar de los Sánchez Muñoz se conservan unas testificaciones sobre las bandas de Marcillas y Muñoces en Teruel en la feria de San Agustín de 1470 y una carta de respuesta dada por los propios Marcillas al juez de Teruel sobre el pacto de una tregua de doce meses ordenada por el rey en las cortes de Monzón de ese mismo año ${ }^{47}$.

Gaspar Juan Sánchez Muñoz y Gamir, nacido en 1483 y único representante de la octava generación de su linaje, fue tutelado como heredero de su padre por su propia madre y por Juan Camañas, según pude recoger en una noticia del 15 de mayo de 1486 en que se mencionaban sus obras benéficas en favor del hospital de Santa María y San Juan de Teruel, entidad de cuya cofradía fue miembro de la junta de gobierno bastantes años más tarde, en $1513^{48}$. Con todo, disponemos de un guión detallado de su trayectoria personal gracias al conocido diario manuscrito que redactó a partir de 1500 , con múltiples noticias autobiográficas y de otras personas de su entorno, entre las cuales aparecen aspectos fundamentales sobre su actividad económica que mencionaré a continuación ${ }^{49}$.

El 4 de octubre de 1499 entró como paje al servicio de Alfonso de Aragón, arzobispo de Zaragoza, según atestigua en su conocido diario manuscrito $^{50}$. En 1501 hizo en compañía de su madre una capilla en la iglesia

${ }^{46}$ LÓPEZ RAJADEL, Crónicas de los jueces, cit., pp. 247, 265-267, 321 y 324-325. El 22 de abril de 1538, Gaspar Juan obtuvo de nuevo el título de barón y señor de Escriche con jurisdicción civil y criminal por documento real de Carlos V, fechado en Barcelona.

${ }^{47}$ AHPT, Fondo de la Familia Sánchez Muñoz, docs. 21 y 28 . Hay asimismo una relación de la gente del bando de los Muñoces que se fecha en el siglo XV (doc. 27).

${ }^{48}$ NaVARro, El hospital de Santa Maria, cit., pp. 577 y 584.

${ }^{49}$ C.J. WitTlin, Les manuscrits dits del papa Luna dans deux inventaires de la bibliothèque de Gaspar Johan S. M. ̀̀ Teruel en "Estudis oferts a Jordi Rubió", vol. 2, Estudis Romànics, XI, Barcelona, 1962-1967, pp. 11-32.

${ }^{50} \mathrm{G}$. LLABRÉS Y QUINTANA, Diario turolense de la primera mitad del siglo XVI, por D. Juan Gaspar Sánchez Muñoz. 1500-1543 en "Boletín de la Real Academia de la Historia", XXVII, julio-septiembre 1895, pp. 5-75.

«Anuario de Estudios Medievales», 32/1 (2002), pp. 723-775 .- ISSN 0066-5061. 
de San Andrés, de Teruel, dedicada a la Virgen del Pilar, la Magdalena y San José, en la que se les concedió enterramiento para ellos y sus sucesores. El 10 de septiembre de 1506 salió del servicio del arzobispo para ir a Teruel a desposarse con Ana Pérez Arnal, hija del señor de Cortes, fallecida en torno a 1515, y con la cual tuvo dos hijos: Honorato y Ana. Hasta entonces alude a numerosas reparaciones que tuvo que realizar en sus heredades a lo largo de esos años, a destacar en mayo de 1508 cuando escribe que rehize el mi molino de ariva arinero, en el cubo, que solia ser trapero, y costó de azerlo arinero segun parece por un memorial de mi mano, quinientos sueldos. Dos años después, en junio de 1510 explica que obré mi tinte del cubo y puse en otra caldera y otra tina, las que estan azia el lavadero, y me costo la dicha obra con el lavadero que se hizo en noviembre de MDIX, dos mil seiscientos sueldos. A la vista están, por tanto, las inversiones que llevaba a cabo este hidalgo en infraestructuras industriales, poniendo de manifiesto un claro comportamiento burgués. Puede decirse que una primera etapa de su vida concluiría el 11 de enero de 1517, con el fallecimiento de su madre por fiebres, enterrándola en la capilla del Pilar antes mencionada.

Dos años después, el 26 de enero de 1519, Gaspar Juan contrajo segundas nupcias con Violante Martínez Malo según certifican sus capitulaciones matrimoniales ante Pedro Jiménez de Teruel, aportando ella una dote de 3.000 sueldos de moneda jaquesa contantes y 67 onzas de plata labrada y variadas piezas de tapicería y ropa de lana ${ }^{51}$. Con Violante tuvo nueve hijos que describe Gaspar en su dietario. El primogénito fue Pedro, quien contraería matrimonio en Zaragoza con María Flores Carrillo y Garcés de Marcilla, que era de la ilustre familia de los condes de Priego, barones de Santa Croche. La segunda hija se llamó Escolástica y fue monja del convento de Santa Clara de Teruel, aportando una dote de 3.000 sueldos. La tercera fue Jerónima, casada con Jaime Bonet de Cedrillas en Teruel. La cuarta hija fue Juana, que sería dama de la duquesa de Segorbe. La quinta fue Juliana, religiosa del monasterio de la Magdalena en Valencia, con una dote de entrada de 2.000 sueldos. El sexto fue Gil, canónigo del

${ }^{51}$ J.L. SotocA, Un documento inédito para la biografia de Gaspar Sánchez Muñoz en “Teruel", 66 (1981), pp. 297-301.

«Anuario de Estudios Medievales», 32/1 (2002), pp. 723-775 .- ISSN 0066-5061. 
Sepulcro de Calatayud. La séptima fue Magdalena que casó en primeras nupcias con Juan Garcés de Marcilla y, en segundas, con Juan Martínez de Marcilla. El octavo hijo de Gaspar se llamó Dionisio y fue caballero y comendador de la Orden de San Juan de Jerusalén. Y por último, la novena hija tuvo por nombre Apolonia y casó con Clemente Iñigo de Santa Olalla. Todos estos datos, complementando al diario en cuestión, se detallan también en la genealogía elaborada por el Barón de la Linde.

El 22 de abril de 1538, Gaspar Juan obtuvo de nuevo el título de barón y señor de Escriche con jurisdicción civil y criminal por documento real de Carlos V, fechado en Barcelona, según recoge en sus memorias. Su testamento lo redactó el 22 de agosto de 1544 en Teruel ante el notario Francisco Gil de Monreal, vinculando la villa y castillo de Escriche con su mero y mixto imperio en favor de su hijo Pedro Sánchez Muñoz y Malo, el primogénito de su segundo matrimonio, en detrimento de su hijo Honorato con quien tuvo ciertas desavenencias. A mediados del siglo XVI, Gaspar Juan murió con más de sesenta años y fue enterrado en su panteón de la iglesia de San Andrés, a la que había enriquecido con muchos y muy notables relicarios de plata, heredados de su tío el antipapa Clemente VIIṔ2. Además, entre 1524 y 1538 puso en marcha su intención de fundar un monasterio de religiosas en el patio llamado del Santo Redentor en la ciudad de Teruel, según evidencian los documentos del fondo familiar ${ }^{53}$.

\section{LOS MARCILLA}

Los enemigos tradicionales de los Sánchez Muñoz también remontan la historia de su familia al tiempo de la conquista de Teruel en el siglo XII, como demuestra el apellido de algunos jueces de la villa por aquel entonces: un tal Sancho o Pedro Pérez de Marcilla (1181-1182), Blasco de Marcilla (1188-1189) y Martín de Marcilla (1192-1193) $)^{54}$. Aunque no será

\footnotetext{
${ }^{52} \mathrm{El}$ diario de Gaspar termina en 1543 y, con letra diferente, en 1555 su primogénito Pedro anotó una noticia sobre las obras de un molino. La muerte de Gaspar debió producirse entre esas fechas, sin olvidar que el testamento lo redactó en 1544, a los 61 años de edad.

${ }^{53} \mathrm{AHPT}$, Fondo de la Familia Sánchez Muñoz, docs. 34-37.

${ }^{54}$ LÓPEZ RAJADEL, Crónica de los jueces, cit., pp. 68-69, 72 y 74.

«Anuario de Estudios Medievales», 32/1 (2002), pp. 723-775 .- ISSN 0066-5061.
} 
hasta un siglo después cuando vuelvan a figurar jueces ostentando dicho apellido como Pedro Martínez de Marcilla (1303-1304), García Martínez de Marcilla (1306-1307), Martín Garcés de Marcilla (1319-1320), Juan Fernández de Marcilla (1341-1342), Miguel Pérez de Marcilla (13461347), Pedro Garcés de Marcilla (1355-1356), Francisco Martínez de Marcilla (1358-1359), Juan Garcés de Marcilla (1366-1367), Miguel Pérez de Marcilla (1370-1371), García Martínez de Marcilla (1372-1373) y Pedro Garcés de Marcilla (1384-1385) ${ }^{55}$. Obsérvese que, a lo largo de esa centuria, ya se habían constituido las principales ramas de Marcillas que habitarán en el Teruel medieval, sobre todo dos, esto es, los Martínez y los Garcés de Marcilla, derivados de un tronco común de antepasados cuyos representantes debieron ser un Martín y un García respectivamente, quizás originarios ambos de la población navarra de Marcilla. Pero no poseemos una genealogía tan completa como en el caso de los Sánchez Muñoz para poder confirmarlo. El esfuerzo de reconstrucción y las incertidumbres son mayores al no conservarse un archivo familiar propio ${ }^{56}$.

En todo caso, sí que es posible elaborar una breve genealogía de los Martínez de Marcilla de Teruel que fueron señores de la baronía de Escriche durante el siglo XV, en competencia directa con los Sánchez Muñoz, quienes recuperarían dicho título, como se ha visto, provocando una cruenta lucha de bandos reflejada en las crónicas en varias ocasiones. En ese sentido, los que siguen a continuación serían los principales representantes del linaje en la Baja Edad Media.

Pedro Martínez de Marcilla, juez en 1303-1304, era hermano de Miguel Pérez de Marcilla, arcipreste y fundador de una capellanía en Santa María de Teruel, según consta en el testamento del propio Miguel redactado en 1327. También de la documentación se deduce que Pedro tuvo dos

\footnotetext{
${ }^{55}$ Ibídem, pp. 122, 130, 142, 146, 168, 170, 184, 192, 194 у 212.
}

\footnotetext{
${ }^{56} \mathrm{Se}$ ha hecho un único intento de reconstrucción genealógica para poder demostrar que la historia de los Amantes de Teruel es una adaptación literaria de la segunda mitad del siglo $\mathrm{XV}$, realizada por un miembro de los Martínez de Marcilla turolenses, aficionado al género historiográfico, y orgulloso de su origen y pertenencia a la pequeña nobleza. Véase F. LÓPEZ RAJADEL, "Los Amantes de Teruel". Una adaptación literaria del siglo XV en "Aragonia Sacra", XI (1996), pp. 63-89.

«Anuario de Estudios Medievales», 32/1 (2002), pp. 723-775 .- ISSN 0066-5061.
} 
hijos por lo menos: García, que fue señor de los molinos de la Vega Dornos, y Martín que se convirtió en canónigo de Santa María de Terue ${ }^{57}$.

García Martínez de Marcilla (difunto en 1335), señor de los molinos, hijo de Pedro y sobrino de Miguel, estuvo casado con Matea Noguera y era padre de García, Martín (casado con Catalina Sánchez) y Elfa (casada con Marco Ruiz de la Roca). Aparece citado como caballero en su testamento ${ }^{58}$.

García Martínez de Marcilla, el hijo primogénito del anterior García, fue juez de Teruel en 1372-1373 como vimos. Estaba casado hacia 1355-1356 con Estefanía Zahera, vecina de Mosqueruela e hija del señor de los molinos de la Vega de Guadalaviar. Tuvo al menos dos hijos de ese matrimonio, llamados Pedro y Martín. Fundó una capilla del Corpus Chris$t i$ en Santa María de Teruel, conjuntamente con sus hermanos ${ }^{59}$.

Pedro Martínez de Marcilla (difunto en 1423), hijo mayor de García y hermano de Martín, perdió su dominio de los molinos de la Vega Dornos en beneficio de su primo homónimo. Pedro estaba casado con Francisca Garcés de Marcilla y era padre de dos hijos, García y Francisca. Fue escudero y regidor de Teruel en 1391, procurador de la ciudad en 1409 y 1414, y según Zurita, capitán de las tropas de seguridad en el Compromiso de Caspe. Hizo testamento en 1422, fundando un aniversario en la capilla de San Simón y San Judas en Santa María de Teruel ${ }^{60}$.

García Martínez de Marcilla (difunto en 1424), hijo de Pedro, figurará desde 1418 como señor de la baronía de Escriche y de las escribanías de Morella. Según unos documentos de 1383, pudo ostentar ese título por estar casado con Elvira López del Roy, hija de Francisca Sánchez Muñoz y Miguel Pérez del Roy, nieta de aquel que fue barón de Escriche, de nombre Juan Sánchez Muñoz, casado con Elvira López, señora de las escriba-

\footnotetext{
${ }^{57}$ TomÁs, Catálogo, cit., docs. 86 y 182.

${ }^{58}$ TomÁs, Catálogo, cit., docs. 86, 116 y 276; TomÁs, Índice, cit., docs. 49 y 53; y LÓPEZ POLO, Catálogo, doc. 81.

${ }^{59}$ TOMÁs, Índice, cit., docs. 48-50 y 115.

${ }^{60}$ TOMÁs, Catálogo, cit., docs. 102, 280, 314 y 452; TOMÁs, Índice, cit., docs. 88, 116, 118 y 266; AGUIRRE y otros, Catálogo, cit., pergs. 142 y 147, pp. 211-212; y J. ZURITA, Anales de la Corona de Aragón, Valencia, Anubar, 1968, libro LXVII, t. 5, p. 201.

«Anuario de Estudios Medievales», 32/1 (2002), pp. 723-775 .- ISSN 0066-5061.
} 
nías de Morella. Es decir, García era yerno de Francisca, uno de los siete hijos de Juan y Elvira, cuyo testamento de 1346 tuvimos oportunidad de comentar. El motivo por el que acabó heredando la tal Francisca los títulos de Escriche y Morella podría ser la muerte sin sucesores o la renuncia de sus cuatro hermanos varones, puesto que ella era la mayor de las tres hijas. Pero el proceso de transmisión de esos títulos no terminaba ahí. Fue en 1418 cuando García Martínez de Marcilla firmó una serie de acuerdos con su cuñado Francisco Pérez del Roy (señor de Escriche) y con Juan Pérez del Roy (vecino de Valencia) para que le cedieran la citada baronía de Escriche y las escribanías de Morella. Finalmente, cabe anotar que tuvo al menos tres hijos (Miguel, Catalina y Antonia), adquiriendo el derecho a ser enterrado en la capilla de San Simón y San Judas ${ }^{61}$.

Miguel Martínez de Marcilla (difunto en 1446), hijo de García, señor de Escriche, se casó en 1422 con Catalina de Funes, hija de Juan Díaz de Funes, hermano del comendador de Cantavieja. Tuvo cinco hijos según parece por la documentación estudiada: Francisco (escudero y futuro heredero de la baronía), García (último heredero de la baronía por la muerte sin sucesión de su sobrino), Luis (canónigo de la colegiata), Gonzalo (vecino de Alfambra) y Alfonso (comendador de Alfambra) ${ }^{62}$.

Francisco Martínez de Marcilla (difunto en 1474), hijo de Miguel y señor de Escriche, estuvo casado con Margarita Placencia y fue padre de Francisco, siendo enterrado en la capilla de San Simón y San Judas de Santa María de Teruel ${ }^{63}$.

Francisco Martínez de Marcilla (difunto en 1480), hijo de Francisco y señor de Escriche, estuvo casado con María Díaz de Molina y no tuvo hijos al menos en el momento de testar, puesto que le sucedió en la baronía de Escriche su tío paterno García Martínez de Marcilla ${ }^{64}$.

Por último, García Martínez de Marcilla (fallecido en 1525), último miembro del linaje en ostentar desde 1482 el título de barón de Escri-

${ }^{61}$ TomÁs, Catálogo, docs. 280-281, 362, 393, 395, 396 y 403.

${ }^{62}$ Ibidem, docs. 411, 412, 465, 470, 474, 475, 476, 517 y 522.

${ }^{63}$ Ibídem, doc. 517.

${ }^{64}$ Aguirre y otros, Catálogo de los Archivos, p. 230, doc. 260.

«Anuario de Estudios Medievales», 32/1 (2002), pp. 723-775 .- ISSN 0066-5061. 
che, se casó hacia 1485 con Violante Cubells, vecina de Morella. En 1515, el rey Fernando el Católico le confirmó la posesión de las escribanías de Morella y, tres años después, hizo lo mismo el emperador Carlos. Dichas escribanías las había recibido en herencia, a medias con su hermano Gonzalo, a quien le compró los derechos. En 1518 haría su testamento dejando las escribanías a su esposa y, posteriormente, a la colegiata de Santa María de Teruel, muriendo en 1525 siendo canónigo de dicha iglesia, momento en el que Gaspar Juan Sánchez Muñoz y otros Marcillas reclamarán la baronía de Escriche ${ }^{65}$.

Sin embargo, durante el siglo XV hay otras dos derivaciones de la familia Martínez de Marcilla en Teruel. Son los Martínez de Marcilla "alias de los Molinos", también llamados "alias de Aranda", cuyos miembros más destacados eran las tres generaciones formadas por Martín el Mayor, su hijo García, y el hijo de éste, de nombre Juan. La otra derivación son los denominados "alias de la Balsa", cuyos miembros más citados en la documentación eran Antón el escudero y sus hijos Martín y Pedro, junto a los hijos de éstos, es decir, Paulo, Pedro y quizá también Ramón y Antón ${ }^{66}$. Los miembros de estas dos derivaciones y no la línea de los señores de Escriche fueron los que participaron en los cargos concejiles de la ciudad de Teruel durante la segunda mitad del siglo XV.

En primer lugar está Pedro Martínez de Marcilla el Mayor, escudero, hijo posiblemente de Antón, que fue regidor (1444-1445, 1452-1453, $1464-1465$ y 1483-1484), jurado (1445-1446, 1453-1454, 1467-1468 y 1471-1472), consejero (1453-1454, 1471-1472, 1473-1474 y 1474-1475), alcalde (1461-1462, 1470-1471 y 1472-1473), síndico y procurador (14681469), y hasta lugarteniente de juez (1472-1473) ${ }^{67}$.

El segundo personaje destacado por la cantidad de puestos que ocupa en el concejo es Ramón Martínez de Marcilla, escudero y jurista, y nieto tal vez de Antón, que fue jurado (1450-1451, 1453-1454, 1465-1466,

\footnotetext{
${ }^{65}$ Ibídem, docs. 467, 523, 524, 597, 615, 618 y 619; y TOMÁS, Índice, cit., docs. 183 192 y 194.

${ }^{66}$ LÓPEZ RAJADEL, "Los Amantes de Teruel", cit., p. 84.

${ }^{67}$ AMT, Concejo, Manuales, 1445-46, 1453-54, 1460, 1461-1462, 1465-66, 1467-68, $1468-69,1469-70,1470-71,1471-72,1473-74,1474-75,1483-84$.
}

«Anuario de Estudios Medievales», 32/1 (2002), pp. 723-775 .- ISSN 0066-5061. 
1467-1468, 1468-1469 y 1473-1474), consejero (1450-1451, 1465-1466, $1467-1468$ y $1470-1471)$, regidor (1455-1456 y 1472-1473) y alcalde $(1474-1475)^{68}$.

A un nivel menor de participación en cargos está Martín Martínez de Marcilla, escudero de difícil identificación entre los homónimos coetáneos de ese apellido, con los puestos de regidor (1455-1456), jurado (14601461) y consejero (1465-1466 y 1470-1471) ${ }^{69}$. Por último, cabe citar a Luis Martínez de Marcilla, escudero, que fue jurado y consejero en 1455-1456, y del cual no tenemos por ahora información sobre su grado de parentesco con los otros escuderos de su apellido ${ }^{70}$.

Fue clara también la implicación de los Martínez de Marcilla en los asuntos de la Inquisición turolense. Me refiero a Beatriz, hija de Pedro Martínez de Marcilla que estaba casada con Pedro Ruiz, hijo de Juan Ruiz y Donosa Besanta. A su vez, el tal Pedro Martínez de Marcilla, padre de Beatriz, se había casado con Violante Ruiz, la hermana de Gil de Gil Ruiz, alias el "Dentudo", e hija de Gil Ruiz el Viejo, de la histórica familia judía Najarí, de quienes hablaré más adelante en el apartado dedicado a los Ruiz. Por último, entre los Martínez de Marcilla que aparecen en los expedientes inquisitoriales merece una mención especial García Martínez de Marcilla, señor de la villa de Escriche y rector de la iglesia parroquial de Caudé, que reclamó de los inquisidores las casas abaciales del canónigo Ram para casa perpetua de la dicha rectoría ${ }^{71}$.

En cuanto a los Garcés de Marcilla, cabe decir que fue esta rama familiar quien en el siglo XIV tomaba la parte más activa en la lucha de bandos contra los Muñoces. En 1355 consta una denuncia contra García y Romeo, hijos del difunto García Garcés y nieto de Pedro Garcés de Marcilla (juez durante 1355-1356), y contra otros dos hijos de este juez llamados Pedro y Juan, por los desmanes que cometieron en la ciudad junto a

${ }^{68}$ AMT, Concejo, Manuales, 1450-51, 1453-54, 1455-56, 1465-66, 1467-68, 1468-69, $1470-71,1472-73,1473-74$ y $1474-75$.

${ }^{69}$ AMT, Concejo, Manuales, 1455-56, 1460, 1465-66 y 1470-71.

${ }^{70}$ AMT, Concejo, Manuales, 1455-56.

${ }^{71}$ SÁNCHEZ MOYA, Los Marcilla y la Inquisición, cit., pp. 182-186.

«Anuario de Estudios Medievales», 32/1 (2002), pp. 723-775 .- ISSN 0066-5061. 
otros muchos del linage e bando clamado de Marcilla... qui eran de treynta personas en susso, e de cinquanta, o xixanta, en yuso ${ }^{72}$.

Desde 1445 también desempeñaron cargos concejiles dos miembros de esta rama. Por un lado, Francisco Garcés de Marcilla, que fue juez (1444-1445), jurado (1445-1446) y alcalde (1481-1482 y 1483-1484). Incluso por las crónicas se sabe que ya había sido juez con anterioridad en 1437-1438 ${ }^{73}$. Asimismo, Luis Garcés de Marcilla ocupó los puestos de alcalde $(1460-1461,1465-1466,1467-1468,1469-1470,1474-1475$ y $1479-$ 1480), consejero (1461-1462, 1468-1469 y 1471-1472), padrón (14701471) y hasta lugarteniente de juez $(1479-1480)^{74}$. En ambos casos la identificación genealógica todavía es muy limitada.

Hay constancia, por ejemplo, del proceso del Santo Oficio de la Inquisición del año 1486 en Teruel contra García Garcés de Marcilla, casado con Leonor, hija de Jaime Martínez de Santángel el Menor, y nieta de Santángel el Mayor, patriarca y mecenas de los judaizantes turolenses, figurando como procurador nuestro Francisco Garcés de Marcilla en representación de García ante el tribunal, sin que podamos saber el grado de parentesco entre ambos, aunque podrían ser hermanos ${ }^{75}$. El proceso en cuestión acusaba a García de favorecedor y cómplice de herejes, no de hereje. De hecho, García y Francisco pasarán a la historia como los principales instigadores desde el concejo de Teruel para evitar la entrada y actuación de la Inquisición en la ciudad. Mientras tanto, es curioso que desde el primer momento, Juan Garcés de Marcilla, asistente o capitán del rey, casado a su vez con Brianda Santángel, estuvo decididamente de parte de los inquisidores. Y eso le atrajo la enemistad de muchos conversos y oficiales turolenses interesados en la frustración del Santo Oficio, tales como Juan de Moros o Martín Martínez Teruel que lo declararon públicamente en la asamblea concejil. Aquí sí que sabemos que el tal Juan era primo de nues-

\footnotetext{
${ }^{72}$ JAVIERRE, Los bandos de los Marcillas..., cit., pp. 370-371.

${ }^{73}$ AMT, Concejo, Manuales, 1445-46, 1481-82 y 1483-84; LÓPEZ RAJADEL, Crónicas de los jueces, cit., p. 242.

${ }^{74}$ AMT, Concejo, Manuales, 1460, 1461-62, 1465-66, 1467-68, 1468-69, 1469-70, 1470 $71,1471-72,1474-75$ y $1479-80$.

${ }^{75}$ SÁnCHEZ MOYA, Los Marcilla ¿empachadores, cit., pp. 113 y 118.

«Anuario de Estudios Medievales», 32/1 (2002), pp. 723-775 .- ISSN 0066-5061.
} 
tro Francisco según recoge Sánchez Moya. Igualmente entre los expedientes inquisitoriales aparece Miguel Garcés de Marcilla, señor de la Torre, en relación con la familia $\mathrm{Ram}^{76}$.

\section{OTRAS FAMILIAS}

\subsection{Abad}

Esta familia de escuderos no aparece en el morabedí de 1384-1387 y parece tratarse de inmigrantes llegados a la ciudad a inicios del siglo XV, puesto que ya consta en el compartimiento de la pecha desde 1420. Entre sus miembros cabe señalar a Juan Abad, que fue juez de Teruel entre 1435 y 1436, habiendo ocupado anteriormente el cargo de alcalde durante 14221423. Según documentos notariales del 8 de julio y del 27 de octubre de 1445 ya había fallecido, actuando como heredero su hijo Martín en la reclamación de 550 sueldos jaqueses que le debía desde 1431 el clérigo Juan Pérez Navarro por el precio de cierta cantidad de trigo. En los protocolos de Pedro Navarro entre 1425 y 1440, Juan Abad aparece identificado como caballero, casado con Violante Jiménez y poseedor de una capellanía en la iglesia de Santa María. Falleció efectivamente en 1440 y el título de su linaje lo heredó su hijo mayor Juan ${ }^{77}$. Por su parte, su otro hijo, el tal Martín Abad, había concordado su matrimonio en presencia del notario Juan Sánchez de Santa María con Francisca Martínez de Marcilla el 5 de mayo de 1445, recibiendo ésta 1.000 sueldos jaqueses en ayuda de su casamiento, los cuales había gastado en ropas de casa. Ese mismo día Martín vendió ante dicho notario ciertas heredades y censales por valor de 27.000 sueldos jaqueses y, un mes antes, el 7 de abril, se le mencionaba en otro

\footnotetext{
${ }^{76}$ SÁNCHEZ MOYA, Los Marcilla y la Inquisición, cit., pp. 186-193. El señorío de la Torre que ostenta Miguel Garcés de Marcilla parece ser que estuvo emplazado en la actual masada de la Torre, en la margen derecha de la carretera de Teruel a Villastar, un kilómetro antes de llegar a esta aldea, según indica el propio Sánchez Moya.

${ }^{77}$ AMT, Concejo, Manuales, 1422-23, 1435-36; Protocolos, Juan Sánchez de Santa María, 1445-47. Véase también LóPEZ RAJADEL, Crónicas de los Jueces, cit., p. 241; MuÑOZ, La ciudad de Teruel, cit., vol. II, p. 477.

«Anuario de Estudios Medievales», 32/1 (2002), pp. 723-775 .- ISSN 0066-5061.
} 
documento como arrendador de corredurías, calificado en todo momento como ciudadano. Además, el 18 de febrero de dicho año figuraba como propietario de una fragua que arrendó a Juan Vicent. Pasado un tiempo, siguió la tradición política de su padre al ocupar los puestos de alcalde del concejo en 1450-1451 y síndico o procurador del mismo en 1453-1454. Finalmente, el 8 de julio de este último año 1454 constará como testigo de un documento del manual del concejo siendo calificado como escudero ${ }^{78}$.

\subsection{Besanta}

Se trata de una de las familias de judeoconversos más importante de la ciudad, emparentada con los Puigmitjà, Ruiz y Santángel entre otros. Berenguer Besanta el Mayor debió convertirse al cristianismo a raíz de las predicaciones de San Vicente Ferrer a principios del siglo $\mathrm{XV}^{79}$. Estaba casado con Clara de Puigmitjà y entre sus hijos estaban Pau y Francisco Besanta, que ocuparon algunos cargos en el concejo turolense, aparte de otras dos personas con el mismo apellido y que se llaman Berenguer y Pedro.

En efecto, Pau Besanta fue regidor (1478-1479) y consejero (14791480 y 1483-1484). Era tendero o mercader, según consta, por ejemplo, el 26 de abril de 1447 ante el notario Juan Sánchez de Santa María en razón de una venta de trigo por valor de 800 sueldos jaqueses. Tanto el 5 de marzo de 1455 como el 7 de mayo del año siguiente constaba en los manuales de actos del concejo como procurador de su padre Berenguer Besanta en sendas ventas de censales. Estaba casado con Castellana Gençor, hija de Salvador, judeoconverso de Valencia. Pau Besanta fue acusado de herejía por los inquisidores en 1486, sin embargo, aparecerá igualmente como contribuyente en el fogaje de $1495^{80}$.

\footnotetext{
${ }^{78}$ AMT, Concejo, Manuales, 1450-51, 1453-54, 1454-55; Protocolos, Juan Sánchez de Santa María, 1445-47.

${ }^{79}$ Sobre los Besanta o Besante véase SÁNCHEZ MOYA y MONASTERIO, Los judaizantes turolenses, XXXII, cit., pp. 130-140.

${ }^{80}$ AMT, Concejo, Manuales, 1455-56, 1479-80 y 1483-84; Protocolos, Juan Sánchez de Santa María, 1445-47; SERRANO, La población de Aragón, cit.; SÁNCHEZ MOYA y MONASTERIO, Los judaizantes turolenses, XXXII, cit., pp. 133-137.

«Anuario de Estudios Medievales», 32/1 (2002), pp. 723-775 .- ISSN 0066-5061.
} 
Francisco Besanta fue consejero (1450-1451, 1465-1466, 1467$1468,1470-1471$ y $1473-1474)$ y regidor (1456-1457 y 1462-1463). El 18 de septiembre de 1454, en el manual de actos del concejo consta como procurador de su padre Berenguer Besanta. Como éste, Francisco también figura en calidad de cofrade de San Sebastián según un documento notarial del 31 de enero de 1445. Con todo, en el año 1481, las crónicas de los jueces de Teruel informan que el cubero Juan de la Vega mató a Francisco Besanta fuera de la puerta de Valencia. Estaba casado con Artesa y su asesinato está confirmado por la documentación inquisitorial ${ }^{81}$.

Otra persona con ese apellido es Berenguer Besanta menor, notario, tendero y mercader, que fue regidor durante 1464-1465. En un documento notarial del 9 de febrero de 1440 constaba ya como viuda su madre Catalina de Galve, mujer que fue de un Berenguer Besanta mayor que no parece ser el judeoconverso, puesto que aquel estaba casado con Clara de Puigmitjà, a no ser que hubiese segundas nupcias. Sea como fuere, en el citado acto notarial, Catalina hacía un préstamo de 600 sueldos en tierras y dinero a varias personas. Asimismo, el difunto Berenguer el mayor ya había sido regidor del concejo durante 1422-1423. En otros documentos ante notario del 5 de febrero de 1442 y del 24 de mayo de 1445, nuestro Berenguer, el menor, realizó sendas ventas de trigo. El 26 de abril de 1447 reclamaba en un nuevo acto notarial 768 sueldos jaqueses y 26 fanegas de centeno que le debía Juan Bernal, vecino de Perales. El 31 de enero de 1445, el notario Juan Sánchez de Santa María lo mencionó en la lectura de unos capítulos como cofrade de San Sebastián ${ }^{82}$.

Por último, está Pedro Besanta, que fue jurado (1453-1454, 14611462 , 1465-1466 y 1467-1468), mayordomo (1455-1456), alcalde (1459$1460,1460-1461,1464-1465,1468-1469,1470-1471$ y $1472-1473)$, lugarteniente de juez $(1460-1461,1464-1465$ y $1470-1471)$, consejero (1461$1462,1469-1470,1471-1472$ y $1474-1475)$, y regidor (1465-1466 y $1473-$ 1474). Aparece identificado como labrador y con el seudónimo de "Fillol"

\footnotetext{
${ }^{81}$ AMT, Concejo, Manuales, 1450-51, 1465-66, 1467-68, 1470-71, 1473-74 y 1483-84; Protocolos, Juan Sánchez de Santamaría, 1445-47; LóPEZ RAJADEL, Crónicas de los jueces, cit., p. 286; SÁNCHEZ MOYA y MONASTERIO, Los judaizantes turolenses, XXXII, cit., p. 138.

${ }^{82}$ AMT, Concejo, Manuales, 1422-23, 1464-65; Protocolos, Juan Sánchez de Santa María, 1442, 1445-47.

«Anuario de Estudios Medievales», 32/1 (2002), pp. 723-775 .- ISSN 0066-5061.
} 
en una petición contra el vino foráneo ante el concejo, fechada el 17 de marzo de $1457^{83}$.

\subsection{Camañas}

Camañas es el topónimo de una aldea de Teruel que desde el siglo XIII aparece como apellido asentado en la ciudad ${ }^{84}$ y son hasta cinco las personas identificadas con dicha denominación entre los listados de cargos concejiles. Para empezar, Luis Camañas, jurista, fue el personaje político más destacado de esta familia y prácticamente de toda la ciudad a finales del siglo XV, por haber ostentado casi todos los cargos significativos del concejo: juez en tres ocasiones (1459-1460, 1469-1470 y 1483-1484); jurado en cuatro (1450-1451, 1455-1456, 1460-1461 y 1470-1471); regidor otras tres (1453-1454, 1470-1471 y 1482-1483); alcalde en cuatro (1461$1462,1464-1465,1468-1469$ y $1471-1472)$; y hasta mayordomo (14651466) y simple consejero $(1467-1468,1473-1474 \text { y } 1481-1482)^{85}$.

Juan Camañas actuó como regidor en 1479-1480, síndico y procurador del concejo en 1481-1482, y alcalde y lugarteniente de juez en 14831484 , siendo aún contribuyente del fogaje aragonés de 1495. Al hablar de Gaspar Juan Sánchez Muñoz ya se indicó que Juan Camañas fue tutor suyo en $1486^{86}$.

Antonio Camañas fue regidor en 1444-1445, alcalde en 1449-1450 y consejero en 1453-1454. Actuó de procurador de su esposa Antonia Alcañiz el 15 de enero de $1446^{87}$. Finalmente, están los hermanos Francisco y Martín Camañas, el primero de los cuales ocupó los puestos de regidor en

${ }^{83}$ AMT, Concejo, Manuales, 1453-54, 1455-56, 1456-57, 1460, 1461-62, 1465-66, $1467-$ $68,1469-70,1470-71,1471-72,1473-74$ y $1474-75$.

${ }^{84}$ Es el caso de Asensio Camañas, juez de Teruel en 1277-1278, véase LóPEz RAJADEL, Crónicas de los jueces, p. 108.

${ }^{85}$ AMT, Concejo, Manuales, 1450-51, 1453-54, 1455-56, 1460, 1461-62, 1465-66, 1467$68,1468-69,1469-70,1470-71,1471-72,1473-74,1481-82$ y $1483-84$.

${ }^{86}$ AMT, Concejo, Manuales, 1479-80, 1481-82 y 1483-84; SERRANO, La población de Aragón, cit.

${ }^{87}$ AMT, Concejo, Manuales, 1445-46, 1450-1451 y 1453-54; Protocolos, Juan Sánchez de Santa María, 1445-57.

«Anuario de Estudios Medievales», 32/1 (2002), pp. 723-775 .- ISSN 0066-5061. 
1449-1450 y consejero en $1450-1451^{88}$. El segundo fue asimismo alcalde en $1450-1451$, regidor en $1452-1453$ y consejero en $1461-1462^{89}$.

El diario de Gaspar Juan Sánchez Muñoz recoge varias noticias sobre los Camañas a principios del siglo XVI, sin duda por la estrecha relación que existió entre ambas familias tal y como demuestra el hecho comentado de que Juan Camañas tutelase a Gaspar a la muerte de su padre. Por ejemplo, cita en 1502 a mosén Antonio Camañas, canónigo, hijo de Juan Camañas y sobrino por tanto del hermano de éste, de nombre Francisco y también canónigo. En 1509 habla de otro Juan Camañas, canónigo, hijo de un tal Miguel. El 24 de enero de 1511 alude al matrimonio de Luis Camañas, hijo de Juan Camañas, con Gracia, hija de Francisco Sánchez de Cutanda, vecino de Camarena, con una dote de 16.000 sueldos, según recogió Gil Pérez, notario de la Puebla de Valverde en esa fecha. De este matrimonio nació un hijo de nombre Luis que murió en 1516. Y en 1520 anota que murió el propio Luis, casado con Gracia, heredando todo su hermano el canónigo Antonio porque no quedaron hijos de él ni de sus herma$\operatorname{nos}^{90}$.

\subsection{Campos}

Los Campos o Sánchez de Campos tienen una primera representación en la figura de Luis de Campos que ocupó los cargos de consejero (1450-1451, 1461-1462, 1465-1466, 1469-1470, 1470-1471 у 1479-1480); regidor (1453-1454, 1460-1461 y 1468-1469); síndico y procurador del concejo (1455-1456 y 1480-1481); alcalde (1464-1465 y 1481-1482); ; jurado (1465-1466, 1467-1468 y 1471-1472); mayordomo (1474-1475) y hasta lugarteniente de juez (1481-1482). Con el nombre de Luis Sánchez de Campos ocupó el cargo de alcalde en dos ocasiones (1449-1450 y 1483-

${ }^{88} \mathrm{AMT}$, Concejo, Manuales, 1450-51.

${ }^{89}$ AMT, Concejo, Manuales, 1450-51, 1453-54 y 1461-62. Véase nota 46 supra.

${ }^{90}$ LlABRÉS, Diario turolense, cit.

«Anuario de Estudios Medievales», 32/1 (2002), pp. 723-775 .- ISSN 0066-5061. 
1484) ${ }^{91}$. Juan de Luîs de Campos debió ser el hijo del anterior, que llegó a ser alcalde en $1498-1499^{92}$.

Asimismo, Miguel de Campos el Mayor, tal vez hermano de Luis, fue consejero en 1483-1484, aunque figuró más veces como Miguel Sánchez de Campos el Mayor, siendo así alcalde (1445-1446, 1459-1460, $1461-1462$, 1478-1479, 1479-1480 y 1482-1483), síndico y procurador (1460-1461), juez (1465-1466), consejero (1468-1469, 1469-1470 y 1471 1472), padrón (1473-1474 y 1479-1480), regidor (1481-1482) y jurado (1481-1482 y 1483-1484), aparte de contribuir al fogaje aragonés de $1495^{93}$. Por su parte, Miguel tuvo un hijo llamado Juan de Miguel de Campos que asumió el cargo de alcalde en 1499-1500, aunque también figuró años antes como Miguel Sánchez de Campos el Menor cuando desempeñó el puesto de jurado (1481-1482) ${ }^{94}$.

\subsection{Jarque}

Existió una familia de conversos en Teruel con el apellido Sánchez Exarch o simplemente Jarque, que emparentó por un lado con los Puigmitjà y por el otro con los de Toledo, destacando la figura de Juan Sánchez Jarque, casado con Tolosana Puigmitjà, de cuyo matrimonio nacieron Violante y Juan. Este Juan Sánchez Jarque se apodaba el "Royo" y estaba casado a su vez con Rita de Toledo, siendo procesado por la Inquisición ${ }^{95}$. La cuestión es que sólo existe una persona que ostente este apellido entre los miembros del concejo turolense, sin que hasta ahora hayamos podido establecer con claridad su grado de parentesco con dicha familia judeoconversa. Esa podría ser una buena hipótesis de trabajo a tenor de la implicación

${ }^{91} \mathrm{AMT}$, Concejo, Manuales, 1450-51, 1453-54, 1455-56, 1460, 1461-62, 1465-66, 1467$68,1468-69,1469-70,1470-71,1471-72,1474-75,1479-80,1481-82$ y 1483-84.

${ }^{92}$ AMT, Concejo, Manuales, 1499-1500.

${ }^{93}$ AMT, Concejo, Manuales, 1445-46, 1460, 1461-62, 1465-66, 1467-68, 1468-69, 146970, 1471-72, 1473-74, 1479-80, 1481-82 y 1483-84; SERRANO, La población de Aragón, cit.

${ }^{94}$ AMT, Concejo, Manuales, 1481-82 y 1499-1500.

${ }^{95}$ Sobre los Sánchez Jarque véase SÁNCHEZ MOYA y MONASTERIO, Los judaizantes turolenses, XXXII, cit., pp. 121-130.

«Anuario de Estudios Medievales», 32/1 (2002), pp. 723-775 .- ISSN 0066-5061. 
directa en el gobierno concejil de otras familias con idéntica condición. Se trata del notario Martín de Jarque que ocupó una larga serie de cargos en el gobierno de la ciudad durante la segunda mitad del siglo XV. Fue jurado (1450-1451 y 1465-1466), alcalde $(1453-1454,1460,1461-1462,1468-$ $1469,1470-1471$ y $1473-1474)$, regidor (1474-1475 y $1480-1481)$, consejero (1461-1462 y 1469-1470), escribano o padrón del concejo (1467-1468), mayordomo (1471-1472), herbajador (1479-1480), y hasta lugarteniente de juez $(1468-1469,1470-1471 \text { y } 1473-1474)^{96}$.

\subsection{Mata}

Tres personas de este apellido ostentaron variados cargos concejiles hacia finales del siglo XV, siendo asimismo todos ellos titulares de fuegos en el censo aragonés de $1495^{97}$. Para empezar está Daniel de la Mata, que fue jurado (1471-1472 y 1479-1480), consejero (1471-1472 y 1479-1480), alcalde (1473-1474, 1478-1479 y 1480-1481), síndico y procurador (14741475 y 1499-1500), lugarteniente de juez (1478-1479), mayordomo (14811482 y 1483-1484) y regidor (1498-1499) ${ }^{98}$. La segunda persona es Juan de la Mata que fue consejero $(1453-1454,1468-1469,1470-1471$ y 1481 1482), regidor (1469-1470, 1473-1474 y 1499-1500), jurado (1470-1471, $1473-1474$ y $1474-1475)$, juez (1471-1472) y alcalde $(1479-1480)^{99}$. Finalmente, está Luis de la Mata que fue regidor (1444-1445 y 1452-1453) y consejero $(1455-1456)^{100}$. Por ahora, la documentación no permite establecer relaciones de parentesco ni una mejor identificación prosopográfica.

\subsection{Moros}

${ }^{96}$ AMT, Concejo, Manuales, 1450-51, 1453-54, 1460, 1461-62, 1465-66, 1467-68, 1468$69,1469-70,1470-71,1471-72,1473-74,1474-75,1479-80$ y $1481-82$.

${ }^{97}$ SerRano, La población de Aragón, cit.

${ }^{98} \mathrm{AMT}$, Concejo, Manuales, 1471-72, 1473-74, 1474-75, 1479-80, 1481-82, 1483-84 у 1499-1500.

${ }^{99}$ AMT, Concejo, Manuales, 1453-54, 1468-69, 1469-70, 1470-71, 1471-72, 1473-74, $1474-75,1479-80,1481-82$ y $1499-1500$.

${ }^{100}$ AMT, Concejo, Manuales, $1445-46,1453-54$ y 1455-56.

«Anuario de Estudios Medievales», 32/1 (2002), pp. 723-775 .- ISSN 0066-5061. 
Los Moros o Sánchez de Moros están representados por Juan y Luis, sin que se sepa exactamente cuál fue su relación de parentesco. En primer lugar, Juan de Moros fue alcalde (1444-1445 y 1478-1479), jurado (1445-1446, 1474-1475 y 1479-1480), consejero (1471-1472, 1473-1474, $1474-1475,1479-1480,1481-1482$ y $1483-1484)$ y juez (1479-1480), aparte de figurar como titular de fuego en $1495^{101}$. Por su parte, Luis de Moros ocupó los cargos de consejero (1455-1456, 1461-1462, 1468-1469 y 14701471), síndico y procurador (1465-1466), regidor (1467-1468, 1472-1473 y $1480-1481)$ y alcalde $(1469-1470,1471-1472,1473-1474$ y 1479-1480), aunque bajo la denominación de Luis Sánchez de Moros consta como juez (1460-1461), lugarteniente de juez (1481-1482 y 1482-1483) y alcalde (1481-1482, 1482-1483 y 1483-1484), además de ser miembro de la junta que gestionaba la administración del hospital de Santa María y San Juan en 1482,1486 y $1488^{102}$.

\subsection{Navarro}

Hasta cinco personas con este apellido desempeñaron puestos de relevancia en el concejo de Teruel. Entre los más destacados está Francisco Navarro que fue jurado (1450-1451, 1455-1456, 1474-1475 y 1483-1484), consejero (1450-1451, 1465-1466, 1468-1469 y 1470-1471), regidor (14531454 y 1464-65), mayordomo (1467-1468 y 1479-1480), alcalde (1469$1470,1478-1479$ y $1480-1481$ ) y juez (1473-1474 y 1481-1482), además de ser contribuyente en el fogaje aragonés de $1495^{103}$.

Juan Navarro, notario, fue alcalde (1444-1445, 1453-1453 y 1471$1472)$, jurado (1445-1446, 1453-1454, 1461-1462, 1479-1480 y $1481-$ 1482), síndico y procurador $(1449-1450,1464-1465,1469-1470$ y $1473-$

${ }^{101}$ AMT, Concejo, Manuales, 1445-46, 1471-72, 1473-74, 1474-75, 1479-80, 1481-82 y 1483-84; SERRANO, La población de Aragón, cit.

${ }^{102}$ AMT, Concejo, Manuales, 1455-56, 1460, 1461-62, 1465-66, 1467-68, 1468-69, 1469-70, 1470-71, 1471-72, 1473-74, 1479-80, 1481-82 y 1483-84; SERRANO, La población de Aragón, cit.; y NAVARRO, El hospital de Santa María, cit.

${ }^{103}$ AMT, Concejo, Manuales, 1450-51, 1453-54, 1455-56, 1465-66, 1467-68, 1468-69, $1469-70,1470-71,1473-74,1474-75,1479-80,1481-82$ y 1483-84; SERRANO, La población de Aragón, cit.

«Anuario de Estudios Medievales», 32/1 (2002), pp. 723-775 .- ISSN 0066-5061. 
1474) y escribano o padrón (1474-1475), aparte de constar como contribuyente en el fogaje aragonés de $1495^{104}$.

El notario Pedro Navarro fue alcalde (1444-1445, 1450-1451, $1452-1453,1454-1455,1455-1456$ y 1481-1482), juez (1445-1446), consejero (1453-1454 y 1473-1474), regidor (1461-1462) y escribano o padrón (1480-1481 y 1483-1484), además de constar en el fogaje aragonés de 1495. En un documento notarial del 15 de febrero de 1436 figura como hijo del ciudadano Jaime Navarro ${ }^{105}$. Por último, estarían Luis Navarro, que fue regidor (1467-1468), jurado (1469-1470 y 1473-1474) y consejero (1473-1474) ${ }^{106}$; y Paulo Navarro el cual sólo consta como juez en 1478$1479^{107}$.

\subsection{Pérez Arnal}

Con el apellido Pérez Arnal destacan tres personas en el conjunto de cargos concejiles turolenses de la segunda mitad del siglo XV. Para empezar, Juan Pérez Arnal el Mayor, mercader y trapero, fue alcalde (1460$1461)$, consejero $(1461-1462,1465-1466,1467-1468,1468-1469$ y $1469-$ 1470), regidor (1464-1465 y 1468-1469), padrón (1465-1466) y jurado (1471-1472), además de ser titular de fuego en $1495^{108}$.

Paralelamente, existe un Juan Pérez Arnal el Menor que debió ser hijo del anterior y que solapa su actividad con aquel en un mismo período. Fue alcalde (1464-1465), jurado (1467-1468, 1469-1470 y 1470-1471), consejero (1467-1468, 1470-1471 y 1474-1475) y síndico y procurador (1473-1474). Hay una referencia en manuales de concejo, fechada el 10 de

${ }^{104}$ AMT, Concejo, Manuales, 1445-46, 1450-51, 1452-53, 1453-54, 1461-62, 1465-66, 1469-70, 1471-72, 1473-74, 1474-75, 1479-80 y 1481-82; SERRANO, La población de Aragón, cit.

${ }^{105}$ AMT, Concejo, Manuales, 1445-46, 1450-51, 1453-54, 1455-56, 1461-62, 1473-74, 1481-82 y 1483-84; Protocolos, Sancho Boyl, 1435-36; SERRANO, La población de Aragón, cit.

${ }^{106}$ AMT, Concejo, Manuales, 1467-68, 1469-70 y 1473-74.

${ }^{107}$ AMT, Concejo, Manuales, 1479-80.

${ }^{108}$ AMT, Concejo, Manuales, 1460, 1461-62, 1465-66, 1467-68, 1468-69, 1469-70, 1471-72 y 1473-74; SERRANO, La población de Aragón, cit.

«Anuario de Estudios Medievales», 32/1 (2002), pp. 723-775 .- ISSN 0066-5061. 
abril de 1456, que alude a la delegación de voto de Juan a favor de su suegro Juan Navarro ${ }^{109}$.

La tercera persona es Miguel Pérez Arnal que ocupó los puestos de regidor (1461-1462), jurado (1465-1466, 1470-1471, 1471-1472, 1473$1474,1474-1475,1479-1480,1481-1482$ y 1483-1484), consejero (1465$1466,1469-1470,1470-1471,1473-1474,1481-1482$ y 1499-1500), síndico y procurador (1467-1468), padrón (1468-1469), herbajador (1469-1470) y regidor $(1474-1475,1479-1480 \text { y } 1483-1484)^{110}$.

El diario de Gaspar Juan Sánchez Muñoz, casado en primeras nupcias con Ana Pérez Arnal recoge bastantes alusiones a esta familia. En 1511 se refiere a los 6.000 sueldos que le prestó su suegro el señor de Cortes para una obra, así como los otros 12.000 que le entregó de dote a su hija cuando se casó. En 1521 menciona el bautismo de un niño del que fueron compadres él y su cuñado el baile. En 1525 y 1526 se nombra a Juan, hijo de Miguel Pérez Arnal, el señor de Cortes, y hermano de Jerónimo Pérez Arnal, baile de Teruel. Este último vendió en 1538 a Fernando de Aragón, duque de Calabria, sus lugares de Viver, Caudiel y El Toro ${ }^{111}$.

\subsection{Puigmitjà}

Estamos ante otra de las principales familias de conversos de Teruel, emparentada con los Sánchez Jarque y los Besanta entre otros. Según los procesos de la Inquisición el origen está en Juan de Puigmitjà, casado con Luna y con cuatro hijos (Francisco, Manuel, Tolosana y Clara), y los dos varones aparecen entre las nóminas de cargos concejiles de Teruel en la segunda mitad del siglo $\mathrm{XV}^{112}$. Primero está Francisco de Puigmitjà, mercader, que fue alcalde (1452-1453 y 1455-1456), consejero (1453-1454, $1469-1470,1474-1475$ y $1479-1480)$, jurado (1460-1461 y 1461-1462), y 1474-75.

${ }^{109}$ AMT, Concejo, Manuales, 1455-56, 1465-66, 1467-68, 1469-70, 1470-71, 1473-74 y

${ }^{110} \mathrm{AMT}$, Concejo, Manuales, 1461-62, 1465-66, 1467-68, 1468-69, 1469-70, 1470-71, 1471-72, 1473-74, 1474-75, 1479-80, 1481-82, 1483-84 y 1499-1500.

${ }^{11}$ LlaBRÉs, Diario turolense, cit.

${ }^{112}$ Sobre los Puigmitjà véase SÁNCHEZ MOYA y MONASTERIO, Los judaizantes turolenses..., XXXII, cit., pp. 110-120.

«Anuario de Estudios Medievales», 32/1 (2002), pp. 723-775 .- ISSN 0066-5061. 
regidor (1470-1471, 1480-1481 y 1483-1484). Su padre era Juan de Puigmitjà tal y como se refleja en un juramento notarial del 12 de marzo de $1447^{113}$. Por su parte, Manuel de Puigmitjà sólo consta como regidor en 1454-1455. Era tendero y mercader según aparece en el arrendamiento de unas tiendas y traperías ante el concejo con fecha 19 de febrero de $1455^{114}$.

Por los expedientes inquisitoriales citados se sabe que el comerciante Francisco de Puigmitjà estuvo casado con Francisca Martínez Rosell, hija de un judío. Tenía una casa cerca de la puerta de Daroca y otra junto a la judería, según el auto de fe celebrado en 1486 contra él. De su matrimonio nacieron cuatro hijos: Manuel (notario), Tolosana, Rica y Violante. Mientras tanto, el regidor Manuel de Puigmitjà, llamado el "Viejo", hijo de Juan y hermano de Francisco, estuvo casado con Gracia, y de dicho matrimonio nació un único hijo, Francisco, apodado el "Largo".

\subsection{Ram}

Según los expedientes inquisitoriales de finales del siglo $\mathrm{XV}$, esta familia de conversos estuvo emparentada con los Ruiz y los Marcilla, y llegó a tener entre sus miembros a un clérigo, Juan Ram, rector de Caudé, lo que demuestra el alto grado de inserción que desarrollaron en la sociedad cristiana a pesar de sus raíces judías. En suma, el árbol genealógico de los Ram se proyecta a partir de tres hermanos: Berenguer (mercader), Juan (clérigo) y Fernando (mercader) ${ }^{115}$. Dos de ellos ocuparon cargos concejiles como se detalla a continuación.

En primer lugar está Berenguer Ram, mercader, tendero o trapero, que fue consejero (1468-1469 y 1481-1482) y regidor (1469-1470, 1472$1473,1479-1480$ y $1483-1484)^{116}$. Según los procesos del Santo Oficio, estuvo casado con la hija de Juan Ruiz y su casa estaba emplazada en la

${ }^{113}$ AMT, Concejo, Manuales, 1453-54, 1455-56, 1460, 1461-62, 1469-70, 1471-72, 1474-75, 1479-80, 1481-82 y 1483-84; Protocolos, Juan Sánchez de Santa María, 1445-47.

${ }^{114}$ AMT, Concejo, Manuales, $1454-55$ y 1455-56.

${ }^{115}$ Sobre los Ram véase SÁNCHEZ MOYA y MONASTERIO, Los judaizantes turolenses..., XXXIII, cit., pp. 325-337.

${ }^{116}$ AMT, Concejo, Manuales, 1468-69, 1469-70, 1473-74, 1479-80, 1481-82 y 1483-84.

«Anuario de Estudios Medievales», 32/1 (2002), pp. 723-775 .- ISSN 0066-5061. 
calle donde vivía Diego de Toledo, otro converso turolense. Heredó los bienes de Mose Najarí, el Naño, tío de su esposa, comprando en 1477 unas casas en la judería por 2.000 sueldos. Tuvo dos hijos, Fernando (casado con Aldonza Ruiz) y Juan. Por añadidura, la confiscación de bienes de la casa de Berenguer y sus hijos se valoró en 21.223 sueldos y 8 dineros, la segunda más rica de la ciudad tras la de Jaime Martínez de Santángel ${ }^{117}$.

$\mathrm{Su}$ hermano Fernando, tendero, trapero, sastre o mercader, fue consejero (1450-1451, 1465-1466, 1467-1468 y 1483-1484) y jurado (1465-1466 y 1469-1470). Además, fue arrendador de tiendas y traperías en los manuales de concejo de febrero de 1455 o marzo de 1467, aunque originariamente debía ser sastre porque así figura como testigo de un documento notarial del 17 de febrero de $1436^{118}$. Por los documentos de la Inquisición se sabe que este Ram se casó con Gracia Jiménez, natural de Calatayud, y en el momento de su procesamiento en 1486 ya había fallecido. Parece ser que en su casa vivían su madre Sendina y su hermano Juan, el clérigo. Una hija suya casó con Miguel Garcés de Marcilla, señor de la Torre.

\subsection{Ruiz}

Del apellido Ruiz sólo está el jurista Gonzalo Ruiz en los cargos de jurado (1481-1482 y 1483-1484) y regidor (1481-1482) ${ }^{119}$. Se trata, sin embargo, de la familia de conversos más poderosa de la ciudad, descendientes del linaje judío de los Najarí, muchos de cuyos miembros fueron procesados por la Inquisición en Valencia y Aragón, y algunos de ellos huyeron a Italia. El origen converso de esta parentela se produjo en 1416, a raíz de la llamada disputa de Tortosa, cuando el judío turolense Samuel Najarí se hizo cristiano para no perder el poder y la influencia que poseía en la corte. Tomó el nombre de Gil Ruiz, y es justo reconocer que la conversión le

${ }^{117}$ FERRER, Aspectos económicos, cit., pp. 286-288.

${ }^{118}$ AMT, Concejo, Manuales, 1450-51, 1454-55, 1455-56, 1465-66, 1466-67, 1467-68, 1469-70 y 1483-84; Protocolos, Sancho Boyl, 1435-36.

${ }^{119}$ AMT, Concejo, Manuales, 1481-82 y 1483-84.

«Anuario de Estudios Medievales», 32/1 (2002), pp. 723-775 .- ISSN 0066-5061. 
abrió nuevas puertas, pues incluso fue armado caballero, algo que en esos momentos pocos judeoconversos habían logrado alcanzar ${ }^{120}$.

En un trabajo reciente sobre la emigración aragonesa a Valencia en los siglos XIV-XVI, he puesto de manifiesto la hipótesis de que Gil Ruiz tuvo por lo menos tres hijos (Gonzalo, Juan y Alfonso), en contraste con siete personas de Teruel avecindadas posteriormente en Valencia: Martín Ruiz, mercader (1417); Gil Ruiz, mercader (1458); Gonzalo Ruiz, doctor en leyes (1460); Leonardo Ruiz, mercader (1462); Gil Ruiz, doncel e hijo de Gonzalo (1466); Gil de Juan Ruiz, mercader (1470); y Gonzalo, hijo de Gonzalo $(1470)^{121}$. Ese jurista de nombre Gonzalo debió volver a Teruel y entre los años 1481-1484 participó en el gobierno concejil. Sus dos hijos Gil y Gonzalo también se marcharon a Valencia como el padre.

Los expedientes de la Inquisición complementan estos datos aludiendo a varias ramas de esta familia en Teruel ${ }^{122}$. Nuestro Gonzalo, el doctor en leyes, estuvo casado con su prima Violante Santángel y tuvo al menos cuatro hijos: Gil, Gonzalo, Gracia (casada con Jaime Martínez de Santángel el Joven) y Violante (casada con Martín Ruiz, escudero y mercader). Era nieto de Gil Ruiz (Samuel Najarí) y hermano de otro Gil Ruiz, posiblemente el mercader avecindado en Valencia en 1458. Asimismo, fue designado por el consejo para asistir a las Cortes de Tarazona de $1484 \mathrm{y}$ actuó junto a su hijo Gil, el doncel, en las negociaciones para la entrada del Santo Oficio en Teruel. Precisamente, el suyo sería el primer auto de fe celebrado en la ciudad. Los bienes confiscados de su casa, incluidos los de su hijo Gil, el doncel, ascendieron a 10.665 sueldos y 2 dineros, la cuarta fortuna más importante de la ciudad, por detrás de Santángel, Ram y sus parientes Gil y Antón Ruiz, cuyos bienes fueron valorados en 15.000 suel-

\footnotetext{
${ }^{120} \mathrm{~F}$. VENDRELL, Concesión de nobleza a un converso en "Sefarad", VIII (1948), p. 397, citado por A. BLASCO MARTÍNEZ, Nuevos datos sobre la judería de Teruel, con especial estudio de sus sinagogas en "Studium. Revista de Humanidades", 3 (1997), pp. 13-43. Sobre la familia Najarí véase especialmente las pp. 26-30 del citado artículo de Blasco.

${ }^{121}$ G. NAVARro EsPINACH, Política municipal y avecindamientos. Análisis de la emigración aragonesa a Valencia (1308-1526) en "Demografía y sociedad en la España bajomedieval”, Universidad de Zaragoza, 2002, pp. 97-128, especialmente pp. 112-114.

${ }^{122}$ Son los Ruiz-Gonzalvo, Ruiz-Gil, Ruiz-Antón y otros Ruiz, al respecto véase SÁNCHEZ MOYA y MONASTERIO, Los judaizantes turolenses, XXXIII, cit., pp. 111-143.
}

«Anuario de Estudios Medievales», 32/1 (2002), pp. 723-775 .- ISSN 0066-5061. 
$\operatorname{dos}^{123}$. Por añadidura, en la documentación notarial y concejil estudiada los Ruiz siempre aparecen calificados de escuderos, aparte de sus calificaciones profesionales individuales.

\subsection{Sánchez Gamir}

Cuatro personas con este apellido figuran en la nómina de cargos del concejo turolense. En primer lugar está Francisco Sánchez Gamir que fue síndico y procurador (1444-1445), jurado (1455-1456, 1460-1461 y 1469-1470), consejero (1455-1456, 1461-1462 y 1469-1470), regidor (1460-1461 y 1471-1472), padrón (1464-1465), alcalde (1465-1466), lugarteniente de juez (1467-1468) y mayordomo (1468-1469 y $1470-1471)^{124}$.

Un segundo personaje destacado es Miguel Sánchez Gamir, mercader, que desempeñó los cargos de jurado (1461-1462, 1465-1466, 14671468 y 1470-1471), y consejero (1467-1468, 1469-1470, 1470-1471, 14711472 y 1483-1484), figurando además repetidamente como miembro de la junta y contable del hospital de Santa María y San Juan durante los años 1489-1500 ${ }^{125}$. Como después veremos, tuvo al menos cuatro hijos: Catalina, Miguel, Gil y Pedro.

La tercera persona es Gil Sánchez Gamir que fue juez (1449-1450) y consejero (1499-1500), si es que no se trata a finales del siglo XV del hijo de Miguel con el mismo nombre. Desde luego, el que fue juez a mediados de la centuría estuvo casado con Aldonza de la Cerda, según aparece como fiadora suya en un arrendamiento ante el concejo, fechado el 27 de junio de $1454^{126}$. Por último, hay que citar a la cuarta persona con este apellido que desempeñó cargos, un tal Juan Sánchez Gamir que fue jurado $(1453-1454)^{127}$.

${ }^{123}$ FERRER, Aspectos económicos, cit., pp. 285-286.

${ }^{124}$ AMT, Concejo, Manuales, 1445-46, 1455-56, 1460, 1461-62, 1465-66, 1467-68, $1468-69,1469-70,1470-71$ y 1471-72.

${ }^{125}$ AMT, Concejo, Manuales, 1461-62, 1465-66, 1467-68, 1468-69, 1469-70, 1470-71, 1471-72 y 1483-84; NAVARRO, El hospital de Santa María, cit.

${ }^{126}$ AMT, Concejo, Manuales, 1450-51, 1454-55 y 1499-1500.

${ }^{127}$ AMT, Concejo, Manuales, 1453-54.

«Anuario de Estudios Medievales», 32/1 (2002), pp. 723-775 .- ISSN 0066-5061. 
También en esta ocasión, el diario de Gaspar Juan Sánchez Muñoz se convierte en fuente de información sobre la familia que nos ocupa, al ser el dicho Gaspar hijo de Catalina, hija a su vez del mercader Miguel Sánchez Gamir. Dicho texto alude en 1515 a los nacimientos de Ana e Isabel Emerenciana, hijas del tío de Gaspar, Miguel Sánchez Gamir, hermano de Catalina y con el mismo nombre que su padre. En 1517 se hace mención a Gil Sánchez Gamir, otro tío de Gaspar que construyó un puente en la ciudad en calidad de procurador de la misma. En 1519 entró como monja de Santa Clara su prima Juana, hija del citado tío Miguel Sánchez Gamir y de su esposa Juana Iñigo, con una dote de 2.000 sueldos y las cosas acostumbradas. En 1520, nació a su otro tío Pedro Sánchez Gamir Navarro un hijo que también se llamó Pedro. En 1522 fueron arrendadores de las sisas generales del reino de Aragón sus primos Gil y Antonio Sánchez Gamir. En 1528, a este primo Antonio y a su esposa Francisca Catalán les nació una hija a la que llamaron Beatriz ${ }^{128}$.

\subsection{Santángel}

En el siglo XV son muy numerosos los individuos que ostentan el apellido Santángel o Martínez de Santángel en los reinos de Aragón y Valencia, en su mayor parte conversos y procedentes de diversos grupos familiares y de diferentes zonas geográficas, lo que ha complicado e impedido, por ahora, su identificación genealógica ${ }^{129}$. En el caso de Teruel, este apellido aparece representado en el concejo por Jaime Martínez de Santángel, trapero y tendero, que fue mayordomo (1445-1446) y consejero (14551456). Debió ser este Jaime, calificado como el "Menor" en su cargo de consejero, el que se avecindó en Valencia en 1457 identificándose como doncel de Teruel ${ }^{130}$.

\footnotetext{
${ }^{128}$ LLABRÉS, Diario turolense, cit.

${ }^{129}$ A. Blasco MARTÍNEZ, Aportaciones documentales para el estudio del origen troncal de los Santángel en "Lluís de Santàngel i el seu temps", Ayuntamiento de Valencia, 1992, pp. 119-131.

${ }^{130}$ AMT, Concejo, Manuales, $1445-46$ y 1455-56; NAVARro, Política municipal y avecindamientos, cit., pp. 111-112.

«Anuario de Estudios Medievales», 32/1 (2002), pp. 723-775 .- ISSN 0066-5061.
} 
Los Santángel de Teruel han podido ser estudiados también a través de los procesos inquisitoriales en que estuvieron inmersos. El origen de esta parentela está en mosén Jaime Martínez de Santángel, caballero, enterrado en la capilla familiar en el convento de San Francisco. Estuvo casado con Rita Ruiz, hija de Gil Ruiz (Samuel Najarí), y tuvo dos hijos: Jaime Martínez de Santángel (llamado el Viejo o el Mayor) y Violante (esposa de Gonzalo Ruiz como vimos). Por su parte, Jaime el Mayor contrajo matrimonio con Rita Besanta y tuvo hasta siete hijos: Jaime Martínez de Santángel (el Menor), Violante, Alfonso, Luis, Brianda, Juan y Alba ${ }^{131}$. En resumen, hay tres Jaimes que corresponden a tres generaciones sucesivas de los Martínez de Santángel en la ciudad de Teruel durante el siglo XV.

Nótese que, de las catorce familias cuyos bienes se confiscaron a través de los procesos inquisitoriales, la hacienda de Jaime Martínez de Santángel II (el Mayor) fue la más rica, valorada en 26.956 sueldos y 2 dineros por la suma de inmuebles, tierras, rentas y negocios diversos. Además, los bienes de su hijo Luis, casado con Brianda Besanta, también fueron requisados por valor de 2.696 sueldos $^{132}$. Los testimonios requeridos en el auto de fe afirmaban que era un comerciante tan rico que tenía dinero para comprar todo Teruel. De hecho, la oposición tenaz al establecimiento de la Inquisición en la ciudad y la propia apelación a Roma debieron ser iniciativa suya ante el concejo, apoyando si fuese preciso la financiación personal de las mismas.

Siguiendo con la documentación procesal, Jaime Martínez de Santángel III (el Menor), el que desempeñaría los cargos de mayordomo y consejero, era mercader de paños (trapero) y tendero. Estuvo casado con su prima hermana Gracia Ruiz y tuvieron cuatro hijos: Leonor, Violante, Juan y otra niña cuyo nombre no se cita. En este punto, recordemos que Brianda, una de las hermanas de Jaime el Menor, procesada asimismo por los inquisidores, paradójicamente era la esposa de Juan Garcés de Marcilla,

\footnotetext{
${ }^{131}$ Sobre los Santángel véase SÁNCHEZ MOYA y MONASTERIO, Los judaizantes turolenses, XXXII, cit., pp. 325-340.

${ }^{132}$ FERRER, Aspectos económicos, cit., pp. 280-283 y 288-289.

«Anuario de Estudios Medievales», 32/1 (2002), pp. 723-775 .- ISSN 0066-5061.
} 
capitán o asistente del rey que apoyó mediante la fuerza militar la introducción del Santo Oficio en Teruel ${ }^{133}$.

\section{RESULTADOS GENERALES}

Hasta 16 familias han centrado el análisis en las páginas anteriores. Son los ejemplos más claros de la compleja red de relaciones que escuderos y burgueses llevaron a cabo en el concejo de Teruel durante el siglo XV para dominar el gobierno local y perpetuarse, por extensión, en su hegemonía social. Sin embargo, es conveniente matizar adecuadamente las cifras. En el Apéndice $n^{\circ} 2$ del presente estudio se presenta el listado total de personas que ocuparon los cargos más importantes del concejo durante 14441500. En conjunto, son 185 personas, de las cuales sólo resulta posible, por ahora, conocer la identidad socioprofesional de 88 , destacando al frente un grupo de 24 notarios y 6 juristas. El resto, aparte de 6 escuderos, son mayoritariamente artesanos y mercaderes en sus diferentes denominaciones, contabilizándose una decena de personas entre labradores y cabañeros de ganado. Salta a la vista, por tanto, que el concepto de burguesía, tal y como fue definido en la letra de los fueros aragoneses medievales, está presente también en la realidad práctica del concejo de Teruel que ilustra nuestra investigación sobre el Cuatrocientos.

Por otra parte, han quedado en el tintero muchos otros datos que no ha sido posible plasmar debido al espacio disponible. Hay personajes que, sin poseer información sobre la trayectoria familiar en que se insertaron, redundan en confirmar desde sus prosopografias individuales el panorama de relaciones descrito y el alto grado de perpetuación en el poder alcanzado a través de determinadas profesiones claves para la administración. Son los casos de Pedro Alfonso (notario y jurista), Luis Benedito (notario), Juan de Burgos (notario), Francisco Cardona, Juan de Galve (notario), Juan Gracián (jurista), Luis Martínez Cano, Guillermo Pérez de Celadas (notario) o Pascual Sebastián (notario), entre otros más. En definitiva, se

\footnotetext{
${ }^{133}$ SÁNCHEZ MoYA, La Inquisición de Teruel y sus judaizantes en el siglo XV. Proceso integro contra Brianda de Santángel, cit.

«Anuario de Estudios Medievales», 32/1 (2002), pp. 723-775 .- ISSN 0066-5061.
} 
ha ofrecido aquí un avance complejo y muy matizado de las elites urbanas turolenses, pero todavía parcial, por estar inmerso en un proyecto más ambicioso que va a permitir a medio plazo ofrecer unos resultados todavía más ricos y densos en detalles. 
APÉNDICE $N^{\circ} 1$

Genealogía de los Sánchez Muñoz

(Línea primogénita del linaje durante los siglos XII-XVI)

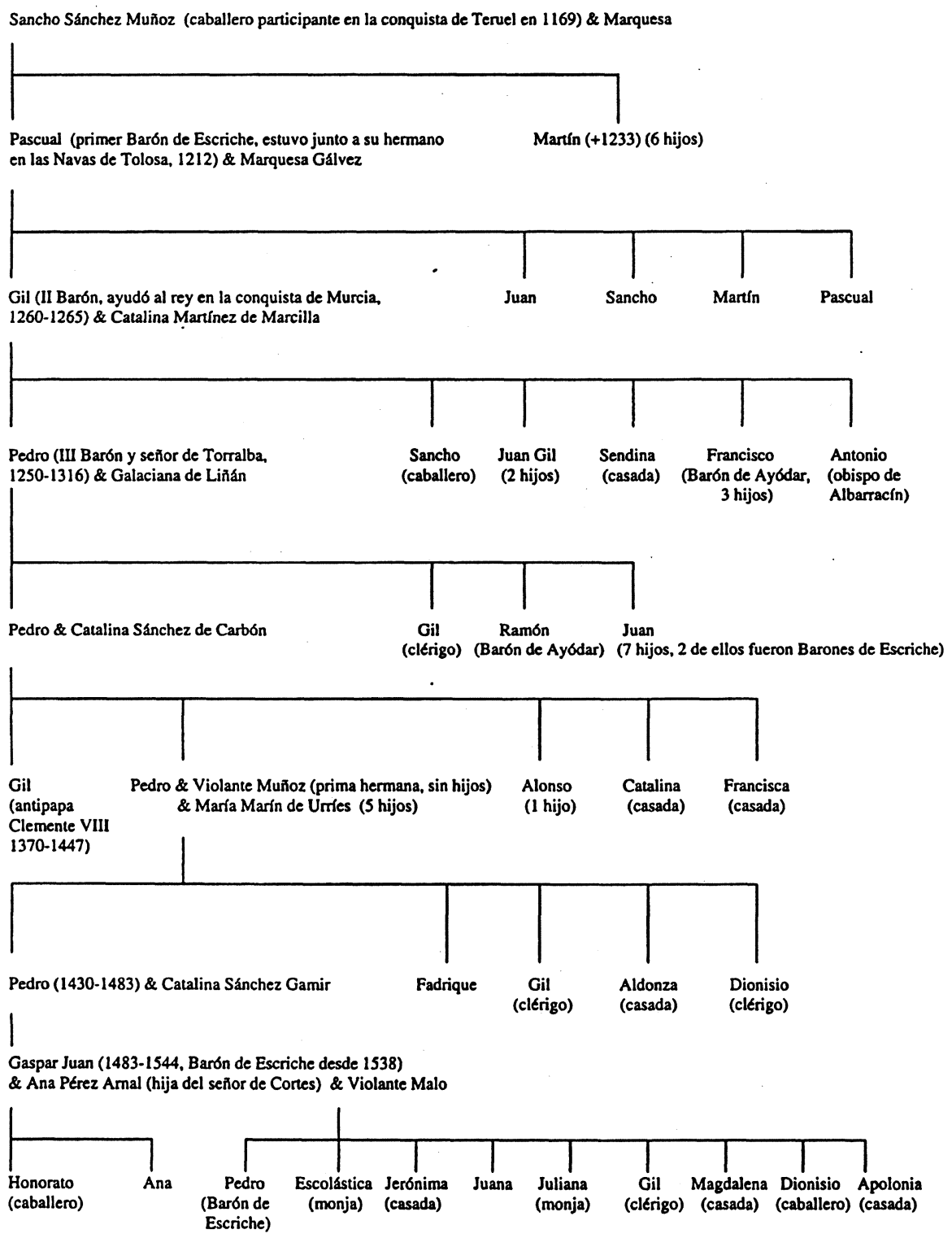




\section{APÉNDICE N ${ }^{\circ} 2$}

\section{LISTADO DE PERSONAS QUE OCUPARON LOS CARGOS MÁS IMPORTANTES DEL CONCEJO DE TERUEL DURANTE 1444-1500}

Fuente: Nóminas de cargos de los Manuales de Concejo. Para identificar las profesiones y oficios de los individuos reseñados se ha utilizado también aquí el vaciado exhaustivo de fuentes que han sido especificadas con anterioridad en nuestro artículo mediante un cuadro de documentación. Entre paréntesis se señalan los años $a$ quo y ad quem entre los cuales ocuparon los cargos que se detallan posteriormente según el orden cronológico en que fueron desempeñados.

Ababuj, Juan de $(1479,1480)$, corredor, consejero.

Abad, Martín (1450, 1454), escudero, alcalde, síndico y procurador.

Abril, Andrés (1498, 1500), alcalde, regidor.

Agustín, Juan (1445, 1446), jurista, regidor.

Alamán, Francisco (1460, 1470), médico, regidor, consejero, mayordomo.

Alamán, Miguel $(1450,1451)$, consejero.

Alavés, Juan de $(1473,1482)$, especiero, regidor, consejero.

Alavés, Pascual de (1461, 1471), consejero.

Alda, Pascual de $(1453,1484)$, regidor, consejero.
Alfonso, Pedro (1455, 1482), notario y jurista, regidor, consejero.

Argente, Juan de $(1472,1473)$, pelaire, juez.

Asensio, Pascual $(1499,1500)$, carnicero, consejero.

Barbastro, Mateo (1449, 1450), regidor.

Beltrán, Juan (1454, 1455), pelaire, regidor.

Bellver, Pedro (1483, 1484), consejero.

Benedito, Bartolomé (1499, 1500), consejero.

Benedito, Luis (1453, 1484), notario, alcalde, síndico y procurador, lugarteniente de juez, jurado, consejero, regidor.

Benedito, Pascual (1445, 1446), padrón. 
Bernabé, Martín de (1473, 1482), labrador, consejero.

Besanta, Berenguer, menor (1464, 1465), notario, tendero y mercader, regidor.

Besanta, Francisco (1450, 1484), consejero, regidor.

Besanta, Pau (1478, 1484), tendero y mercader, regidor, consejero.

Besanta, Pedro, alias Fillol (1453, 1475), labrador, jurado, mayordomo, alcalde, lugarteniente de juez, consejero, regidor.

Blasco, Pedro (1499, 1500), regidor.

Burgos, Jaime de $(1469,1470)$, padrón.

Burgos, Juan de $(1449,1472)$, notario, alcalde, regidor, jurado, síndico y procurador, consejero.

Cabrero, Bernardo (1453, 1470), barbero y pelaire, consejero.

Cabronero, Juan $(1465,1482)$, consejero.

Calvo, Juan, el Menor (1467, 1475), labrador y cabañero, consejero.

Calvo, Pedro (1455, 1456), labrador, consejero.

Calvo, Simón (1473, 1474), cabañero, regidor.

Camañas, Antonio $(1444,1454)$, regidor, alcalde, padrón, consejero.

Camañas, Francisco (1449, 1454), regidor, consejero, padrón.

Camañas, Juan $(1479,1484)$, regidor, síndico y procurador, alcalde, lugarteniente de juez.
Camañas, Luis (1450, 1484), jurista, jurado, regidor, juez, alcalde, mayordomo, consejero.

Camañas, Martín $(1450,1462)$, alcalde, regidor, consejero.

Campillo, Domingo (1450, 1475), coracero, consejero.

Campos, Juan de Luis de (1498, 1499), alcalde.

Campos, Juan de Miguel de (1499, $1500)$, alcalde.

Campos (o Sánchez de Campos), Luis de $(1449,1484)$, alcalde, consejero, regidor, síndico y procurador, jurado, mayordomo, lugarteniente de juez.

Campos (o Sánchez de Campos), Miguel de, el Mayor (1445, 1484), alcalde, síndico y procurador, juez, consejero, padrón, jurado.

Campos (o Sánchez de Campos), Miguel de, el Menor (1481, 1482), jurado.

Cano, Francisco $(1459,1460)$, regidor.

Cañegral, Alejandro (1499, 1500), zapatero, consejero.

Capilla, Pedro $(1480,1481)$, juez.

Cardona (o Sánchez Cardona), Francisco $(1450,1475)$, jurado, consejero, juez, alcalde, regidor, lugarteniente de juez.

Carrión, Juan, el Menor (1499, 1500), consejero.

Cebrián, Fernando (1461, 1462), regidor.

Cedrillas, Gonzalo (1468, 1484), barbero, consejero. 
Cedrillas, Juan (1499, 1500), barbero, consejero.

Concud, Martín (1469, 1470), regidor.

Cueva, Gonzalo de la $(1465,1472)$, notario, regidor, juez, jurado, consejero.

Cuevas, Gil de las (1499, 1500), consejero.

Cuevas, Miguel de las $(1483,1484)$, síndico y procurador.

Díaz, Pedro $(1479,1480)$, zapatero, consejero.

Dolz, Jaime (1483, 1500), notario, jurado, padrón.

Dolz, Pedro (1468, 1499), juez.

Domínguez de Ocón, Gil (1474, 1475), juez.

Domínguez del Mesado, Francisco $(1455,1466)$, notario, consejero, síndico y procurador.

Escorihuela, Nicolás de (1465, 1470), herrero, consejero.

Escudero, Martín $(1453,1454)$, síndico y procurador.

Esteban, Juan (1468, 1475), notario, consejero.

Esteban, Lorenzo (1470, 1472), consejero, regidor.

Fernández, Juan $(1445,1446)$, herrero, jurado.

Ferrero, Antonio (1450, 1475), notario, consejero, regidor.

Ferreruela, Pedro (1483, 1484), labrador, consejero.

Fons, Esteban $(1470,1471)$, tendero, consejero.

Forter, Antonio (1470, 1471), consejero.
Fortún, Juan $(1471,1472)$, consejero.

Foz, Pascual de la $(1445,1480)$, labrador y cabañero, regidor, síndico y procurador, consejero.

Galve, Francisco de $(1445,1451)$, síndico y procurador, juez.

Galve, Juan de (1452, 1484), notario, regidor, consejero, jurado, padrón, mayordomo.

Garcés de Marcilla, Francisco (1444, 1484), juez, jurado, alcalde.

Garcés de Marcilla, Luis (1460, 1480), alcalde, consejero, padrón, lugarteniente de juez.

García, Gaspar $(1499,1500)$, consejero.

Garín, Juan (1450, 1451), notario, consejero.

Gascón, Juan (1444, 1446), regidor, alcalde, lugarteniente de juez.

Gasconilla, Gil de $(1453,1454)$, consejero.

Gil, Fernando $(1455,1456)$, pelaire y tendero, consejero.

Gil, Salvador, el Menor (1467, 1468), tintorero, consejero.

Gil de Falomir, Juan $(1470,1471)$, juez.

Gil de Moros, Domingo (1445, 1461), notario, regidor, jurado.

Gracián, Gil $(1474,1484)$, consejero, regidor.

Gracián, Juan $(1449,1484)$, jurista, regidor, consejero, jurado, síndico y procurador.

Gregori, Lluc (1498, 1500), síndico y procurador, consejero.

«Anuario de Estudios Medievales», 32/2 (2002), pp. 723-775 .- ISSN 0066-5061. 
Iñigo, Juan (1469, 1480), jurado, síndico y procurador, alcalde, consejero, regidor.

Jarque, Martín de (1450, 1482), notario, jurado, alcalde, consejero, padrón, lugarteniente de juez, mayordomo, regidor.

Jiménez, Alfonso (1479, 1484), notario, consejero, jurado, alcalde.

Jiménez, Juan (1445, 1446), notario, alcalde, lugarteniente de juez.

Jiménez, Martín (1499, 1500), consejero.

Jordán, Jaime (1469, 1470), platero y tendero, síndico y procurador.

Jordán, Miguel (1460, 1461), barbero y cirujano, regidor.

Laparra, Francisco (1461, 1462), consejero.

Lidón, Pedro (1479, 1484), hostalero, consejero.

López de Castiel, Juan (1481, 1500), coracero y tendero, consejero.

López-de Monreal, Francisco (1445, 1451), notario, regidor, síndico y procurador, consejero.

Lorenzo, Juan (1450, 1451), carnicero, consejero.

Maestro, Domingo (1465, 1482), regidor.

Martín, Arnau (1461, 1462), regidor.

Martín, Miguel (1482, 148ß̧)ęz.

Martínez, Francisco (1461, 1462), jurado.

Martínez, Luis, el Mayor (1498, 1500), regidor, mayordomo.
Martínez, Luis, el Menor (1499, 1500), consejero.

Martínez, Pedro (1480, 1481), regidor.

Martínez Cano, Luis (1474, 1499), síndico y procurador, alcalde, jurado, consejero, lugarteniente de juez.

Martínez de Ateca, Antonio (1453, 1475), especiero, consejero, regidor.

Martínez de Marcilla, Luis (1455, 1456), escudero, jurado, consejero.

Martínez de Marcilla, Martín (1455, 1471), escudero, regidor, jurado, consejero.

Martínez de Marcilla, Pedro, el Mayor $(1444,1475)$, escudero, regidor, jurado, consejero, alcalde, síndico y procurador, lugarteniente de juez.

Martínez de Marcilla, Ramón (1450, 1475), escudero y jurista, jurado, consejero, regidor, alcalde.

Martínez de Santángel, Jaime (1445, 1456), trapero y tendero, mayordomo, consejero.

Martínez Teruel, Martín (1481, 1482), consejero.

Mata, Daniel de la (1471, 1500), jurado, consejero, alcalde, mayordomo, regidor, síndico y procurador.

Mata, Juan de la $(1453,1500)$, consejero, regidor, jurado, juez, alcalde.

Mata, Luis de la $(1444,1456)$, regidor, consejero. 
Miedes, Juan de, el Mayor (1450, 1469), labrador y cabañero, consejero.

Mojón, Pedro (1483, 1484), consejero.

Mongalián, García de $(1452,1454)$, barbero y carnicero, consejero.

Montalbán, Pedro (1455, 1456), regidor.

Monterde, Pedro $(1464,1465)$, juez.

Moros, Juan de $(1444,1484)$, alcalde, jurado, consejero.

Moros (o Sánchez de Moros), Luis de $(1455,1483)$, juez, alcalde, lugarteniente de juez, consejero, síndico y procurador, regidor.

Muñoz, Francisco (1461, 1472), notario, consejero, síndico y procurador, regidor.

Navarrete, Francisco (1455, 1456), consejero.

Navarro, Francisco (1450, 1484), jurado, consejero, regidor, mayordomo, alcalde, juez.

Navarro, Juan (1444, 1482), notario, alcalde, jurado, síndico y procurador, padrón.

Navarro, Luis (1467, 1474), regidor, jurado, consejero.

Navarro, Paulo (1478, 1479), juez.

Navarro, Pedro $(1444,1484)$, notario, alcalde, juez, consejero, regidor, padrón.

Navarro de Ainar, Pedro (1445, 1456), alcalde, mayordomo, consejero, jurado.

Navarro de Villalba, Francisco (1454, 1455), juez.
Obón (o Pérez de Obón), Sancho de $(1455,1484)$, labrador, consejero, síndico y procurador, regidor.

Orihuela (o Sánchez de Orihuela), Juan de $(1445,1484)$, jurista, jurado, consejero, padrón.

Orrios, Sebastián de $(1498,1500)$, regidor, consejero.

Pascual, Juan (1450, 1451), pelaire, consejero.

Pérez, Francisco $(1498,1500)$, notario, regidor, consejero.

Pérez, Pedro de Pedro Guillem (1483, 1500), consejero, alcalde. Pérez, Pedro Guillem de Guillem (1483, 1484), jurado.

Pérez, Sancho $(1453,1454)$, especiero, consejero.

Pérez Arnal, Juan, el Mayor (1460, 1473), mercader y trapero, alcalde, consejero, regidor, padrón, jurado.

Pérez Arnal, Juan, el Menor (1464, 1475), alcalde, jurado, consejero, síndico y procurador.

Pérez Arnal, Miguel (1461, 1500), regidor, jurado, consejero, síndico y procurador, padrón.

Pérez de Celadas, Guillermo (1454, 1480), notario, regidor, jurado, juez, consejero.

Pérez de Sadornil, Miguel (1445, 1462), regidor, alcalde, jurado, consejero.

Pérez de Villel, Antonio (1445, 1446), alcalde.

Pérez Garín, Juan $(1461,1462)$, notario, mayordomo. 
Povo, Mateo el (1499, 1500), labrador y zapatero, consejero.

Puigmitjà, Francisco de (1452, 1484), mercader, alcalde, consejero, jurado, regidor.

Puigmitjà, Manuel de (1454, 1455), tendero y mercader, regidor.

Quiñonero, Jaime (1455, 1456), barbero y cirujano, consejero.

Rajadel, Berenguer (1468, 1475), regidor, consejero.

Rajadel, Miguel (1481, 1482), notario, consejero.

Ram, Berenguer (1468, 1484), mercader, tendero y trapero, consejero, regidor.

Ram, Fernando $(1450,1484)$, tendero, trapero, sastre, mercader, consejero, jurado.

Ruiz, Gonzalo (1481, 1484), jurista, regidor, jurado.

Sadornil, Francisco (1499, 1500), alcalde.

Sadornil, Juan (1453, 1456), consejero, juez.

Sadornil de Argente, Juan (1453, 1456), jurado.

Sala, Juan (1468, 1483), jurado, consejero, alcalde, lugarteniente de juez, regidor.

Sánchez de Campos, García (1467, 1468), regidor.

Sánchez de Santa María, Juan (1445, 1454), notario, jurado, mayordomo.

Sánchez de Santa María, Pedro (1453, 1454), alcalde.

Sánchez Gamir, Francisco (1444, 1472), síndico y procurador, ju- rado, consejero, regidor, padrón, alcalde, lugarteniente de juez, mayordomo.

Sánchez Gamir, Gil (1449, 1500), juez, consejero.

Sánchez Gamir, Juan (1453, 1454), jurado.

Sánchez Gamir, Miguel (1461, 1472), mercader, jurado, consejero.

Sánchez Gamir, Pedro (1498, 1500), alcalde, juez.

Sánchez Muñoz, Gil (1445, 1456), regidor, consejero.

Sarnes, Pedro (1445, 1446), jurado.

Sebastián, Pascual (1445, 1475), notario, síndico y procurador, jurado, juez, regidor, consejero.

Soria, Juan de (1473, 1474), consejero.

Toledo, Diego de (1474, 1475), jurado, consejero.

Torres, Francisco $(1482,1500)$, tejedor, regidor, consejero.

Valdecebro, Andrés de (1479, 1484), consejero.

Valdecebro, Juan de (1499, 1500), consejero.

Valero, Vicente $(1467,1468)$, regidor.

Vallacroche, Antonio de (1450, 1454), labrador, consejero.

Vallacroche, Pedro (1481, 1500), consejero.

Vicent, Jaime (1464, 1500), candelero, regidor.

Vijuesca, Diego de (1478, 1500), notario, síndico y procurador, consejero, alcalde. 
Villaespesa, Aparicio (1461, 1482), padrón, consejero, jurado, alcalde, síndico y procurador, regidor.

Villaespesa, Onofre $(1473,1474)$, especiero, consejero.
Villalba, Francisco (1461, 1462), notario, consejero.

Villalba, Nicolás de $(1455,1475)$, tendero, consejero, regidor.

Villar, Juan del $(1481,1482)$, pintor, consejero. 